\title{
Murine Bone Marrow Mesenchymal Stromal Cells Respond Efficiently to Oxidative Stress Despite the Low Level of Heme Oxygenases 1 and 2
}

\author{
Witold Norbert Nowak, Hevidar Taha,,2 Neli Kachamakova-Trojanowska, Jacek Stępniewski, \\ Joanna Agata Markiewicz, Anna Kusienicka,' Krzysztof Szade,, Agata Szade, Karolina Bukowska-Strakova, ${ }^{1,3}$ \\ Karolina Hajduk,, Damian Klóska,' Aleksandra Kopacz, Anna Grochot-Przęczek,' Kathrin Barthenheier, \\ Camille Cauvin, Józef Dulak, ${ }^{1,4}$ and Alicja Józkowicz ${ }^{1}$
}

\begin{abstract}
Aims: Mesenchymal stromal cells (MSCs) are heterogeneous cells from adult tissues that are able to differentiate in vitro into adipocytes, osteoblasts, or chondrocytes. Such cells are widely studied in regenerative medicine. However, the success of cellular therapy depends on the cell survival. Heme oxygenase-1 (HO-1, encoded by the Hmoxl gene), an enzyme converting heme to biliverdin, carbon monoxide, and $\mathrm{Fe}^{2+}$, is cytoprotective and can affect stem cell performance. Therefore, our study aimed at assessing whether Hmoxl is critical for survival and functions of murine bone marrow MSCs.

Results: Both MSC Hmoxl $I^{+/+}$and $H$ moxl $I^{-/}$showed similar phenotype, differentiation capacities, and production of cytokines or growth factors. Hmoxl $I^{+/+}$and HmoxI $I^{-/}$cells showed similar survival in response to $50 \mu \mathrm{mol} / \mathrm{L}$ hemin even in increased glucose concentration, conditions that were unfavorable for Hmoxl ${ }^{-1-}$ bone marrowderived proangiogenic cells (BDMC). Hmoxl ${ }^{+/+}$MSCs but not fibroblasts retained low ROS levels even after prolonged incubation with $50 \mu \mathrm{mol} / \mathrm{L}$ hemin, although both cell types have a comparable Hmoxl expression and similarly increase its levels in response to hemin. MSCs Hmoxl $I^{-/-}$treated with hemin efficiently induced expression of a vast panel of antioxidant genes, especially enzymes of the glutathione pathway.

Innovation and Conclusion: Hmoxl overexpression is a popular strategy to enhance viability and performance of MSCs after the transplantation. However, murine MSCs Hmoxl ${ }^{-/-}$do not differ from wild-type MSCs in phenotype and functions. MSC $\mathrm{Hmoxl}^{-/-}$show better resistance to hemin than fibroblasts and BDMCs and rapidly react to the stress by upregulation of quintessential genes in antioxidant response. Antioxid. Redox Signal. 29, 111-127.
\end{abstract}

Keywords: stem cells, antioxidant gene response, heme, mesenchymal stem cell

\section{Introduction}

$\mathbf{M}$ ESENCHyMal STROMal CELls (MSCs), also known as mesenchymal stem cells, or multipotent stromal cells are a heterogeneous population of connective tissue cells that contains osteoblast and adipocyte progenitors, fibroblasts, and smooth muscle cells (5). In vitro criteria for human MSCs include adherence to the plastic in standard culture conditions, differentiation in vitro to adipocytes, osteoblasts, and chondrocytes (9). MSCs should express CD73, CD90, and CD105 markers but not CD45, CD34, CD14, CD11b, CD79 $\alpha$, CD19, and HLA-DR (9). MSCs were further identified, also in vivo, by CD271 and CD106 (human) (33), CD146 (44), nestin (34), Sca-1 (mouse) and PDGFR $\alpha$

\footnotetext{
${ }^{1}$ Department of Medical Biotechnology, Faculty of Biochemistry, Biophysics and Biotechnology, Jagiellonian University, Kraków, Poland.

${ }^{2}$ Department of Animal Production, College of Agriculture, University of Duhok, Duhok, Iraq.

${ }^{3}$ Department of Clinical Immunology, Institute of Pediatrics, Jagiellonian University Medical College, Kraków, Poland.

${ }^{4}$ Kardio-Med Silesia, Zabrze, Poland.
} 


\section{Innovation}

Enhancement of stem and progenitor cells antioxidant capacity is the aim of many studies focusing on the cellular therapies. Many of such strategies propose the overexpression of Hmoxl as a protection against cell stress. For the first time, this article shows that mesenchymal stromal cells (MSCs) lacking Hmoxl can more efficiently than other cells deal with oxidative stress induced with hemin, using the mechanism involving the upregulation of glutathione pathway. High resistance to stress and unique ability to activate antioxidant response suggest that MSC may not need additional protection by Hmoxl overexpression.

(36), leptin receptor $\operatorname{LepR}(8,67)$, or high expression of CXCL12 (41).

MSCs were shown to be immune evasive or immunomodulatory, depending on the microenvironment (2). The mechanism of immunosuppression is complex and involves many factors, that is, prostaglandin E2, nitric oxide, and TGF $\beta$ (39). Although MSCs are commonly believed to deal with oxidative stress efficiently (55), the biggest obstacle to the therapeutic use of MSCs is their poor survival and engraftment after the transplantation (11). Therefore, many studies focus on the enhancement of their antioxidant activity with overexpression of various genes, for example, Hmoxl $(54,63)$.

Heme oxygenase-1 (HO-1, encoded by the HMOX1 gene) is an enzyme degrading heme to carbon monoxide (CO), biliverdin, and $\mathrm{Fe}^{2+}$ ions. Due to its enzymatic activity, heme oxygenase-1 influences cell survival, resistance to the oxidative stress, and angiogenesis (10). We have recently shown that proangiogenic cells isolated from the bone marrow of Hmoxl knock-out mice present impaired proliferation, migration, and formation of capillaries (16). What is more, overexpression of heme oxygenase- 1 can lead to the block of differentiation, that is, in myoblasts (27).

Rat MSCs transfected with the plasmid coding for human heme oxygenase- 1 showed decreased apoptosis in hypoxia and higher resistance to $\mathrm{H}_{2} \mathrm{O}_{2}(54)$. In our hands, pig bone marrowderived cells transduced with adenoviral vectors encoding heme oxygenase-1 (AdHO1) were characterized by better angiogenic activity in vitro and improved left ventricular ejection fraction $30 \mathrm{~min}$ after infarction in pigs (63). Treatment with cobalt protoporphyrin IX (CoPP), heme oxygenase-1 activator, enhanced proliferation of human mesenchymal stem cells and production of VEGF; whereas tin protoporphyrin IX (SnPP), heme oxygenase-1 inhibitor, had an opposite influence (20). Further, CoPP-treated MSCs accelerated wound healing in a xenogeneic model of diabetic mice (20).

Modulation of heme oxygenase-1 activity with SnPP in human MSCs affected their ability to inhibit T cell proliferation in vitro. Interestingly, the effect of SnPP was not observed in rat MSCs, and T cell proliferation was restored only when concomitant treatment of nitric oxide synthase 2 was used (7). Moreover, heme oxygenase inhibition decreased the ability of MSCs to induce Tr1 and Th3 regulatory cells and to elevate levels of IL-10 and TGF $\beta$, respectively. MSCs preconditioned with a mixed lymphocyte reaction showed decreased HO-1 levels as well as immunomodulatory activity (37).
Finally, the effect of heme oxygenase-1 on MSC differentiation to adipocytes and osteoblasts was also studied. Abraham and co-workers showed in the series of publications that enhanced expression of HO-1 in MSCs results in improved differentiation to osteoblasts, whereas its inhibition promotes adipogenesis $(3,56-59)$. On the other hand, Zarjou et al. reported no differences in differentiation potential between MSC Hmox $I^{+/+}$and Hmox $I^{-/-}$(66). Also in other studies, overexpression of heme oxygenase-1 in MSCs did not affect their differentiation $(18,68)$.

Data on the influence of heme oxygenase-1 on MSCs are often contradictory. Conjointly, copper or tin protoporphyrins were used in many studies to modulate HO-1 activity, although they were shown to have many heme oxygenase-independent effects in various cell types $(17,23)$. MSCs are essential for the proper function of stem cell niches in bone marrow, and lack of heme oxygenase- 1 was shown to potently affect other bone marrow-derived cells, that is, pro-angiogenic cells (PACs) (16). Therefore, we decided to characterize murine bone marrowderived MSCs lacking the functional Hmoxl gene, with the focus on their response to oxidative stress.

\section{Results}

\section{$\mathrm{Hmox}^{+/ /+}$or $\mathrm{Hmox} 1^{-/}$bone marrow MSCs show similar phenotype and differentiation}

First, we compared the phenotypes of murine bone marrow stromal cells $\mathrm{Hmox}_{\mathrm{I}^{+/+}}$or Hmox1 $\mathrm{I}^{-/-}$in culture by using flow cytometry. Regardless of the genotype, $60 \%$ of the cells in culture were CD $45^{-} \mathrm{CD} 31^{-}$(data not shown). Therefore, cells used for all the experiments were purified from the remaining $\mathrm{CD}_{4} 5^{+}$fraction with MACS sorting. Obtained cells lacked expression of endothelial markers CD31 and CD34, whereas CD117 (c-kit) was expressed only on a small sub-fraction of cells (Fig. 1A). Isolated MSCs expressed positive markers that were attributed to the mesenchymal stem/stromal cells, that is, CD29, CD90, CD105, Ly-6A/E (Sca-1) (Fig. 1B), and CD140a (PDGFR $\alpha)\left(\right.$ Fig. 1C, D). Hmox ${ }^{-1-}$ bone marrowderived PACs had impaired proliferation (16). However, the proliferation of MSC Hmoxl $1^{+/+}$or $H \operatorname{mox} 1^{-/-}$was similar, even when cells were grown under stress conditions in high glucose concentration (Fig. 2A).

Further, bone marrow stromal cells isolated from long bones of mice $\operatorname{Hmox}_{1} \mathrm{I}^{+/}$or Hmoxl $\mathrm{I}^{-/-}$formed similar numbers of colonies that consisted of fibroblastoid cells (Fig. 2B) or cells able to be differentiated to osteoblasts (Fig. 2C). MSCs were shown to differentiate into adipocytes, osteoblasts, and chondrocytes (6). Both Hmoxl ${ }^{+/+}$and Hmoxl $1^{-1-}$ MSCs differentiated into osteoblasts and adipocytes, which were evidenced with staining for osteopontin or Fabp4, respectively (Supplementary Fig. S1A, B; Supplementary Data are available online at www.liebertpub.com/ars).

Because HO-1 was suggested to play a crucial role in the regulation of MSC adipogenesis (59), we focused on the effects of Hmoxl knockout on the genes associated with lipid metabolism. Interestingly, differentiation of murine bone marrow MSCs to adipocytes induced similar changes in the gene expression in both Hmox $\mathrm{I}^{+/+}$and Hmoxl $^{-/-}$cells (Supplementary Fig. S1C).

However, Hmox $1^{+/+}$MSCs were the only ones that increased expression of miR-21-5p, the microRNA that, via TGF $\beta$ signaling, regulates adipogenesis (26) (Supplementary 
Negative markers
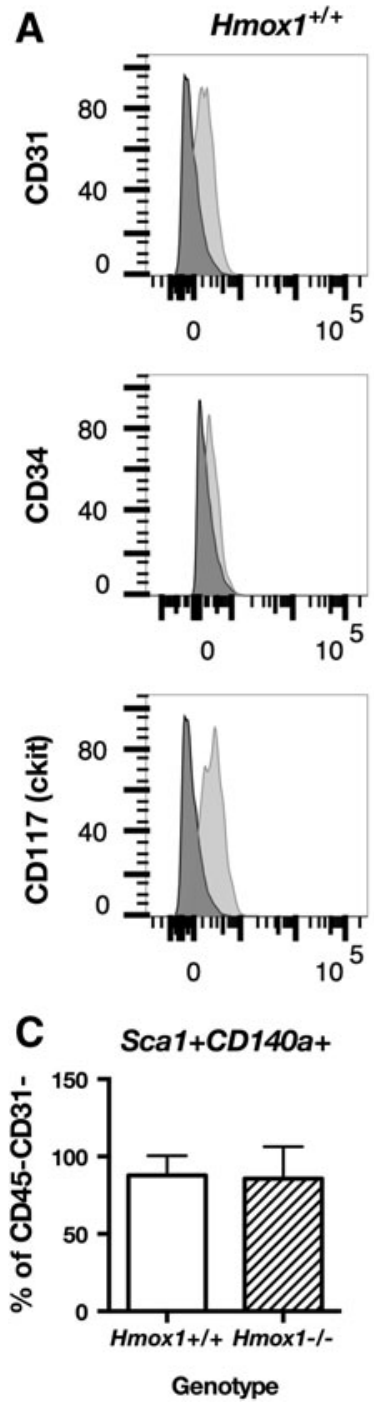
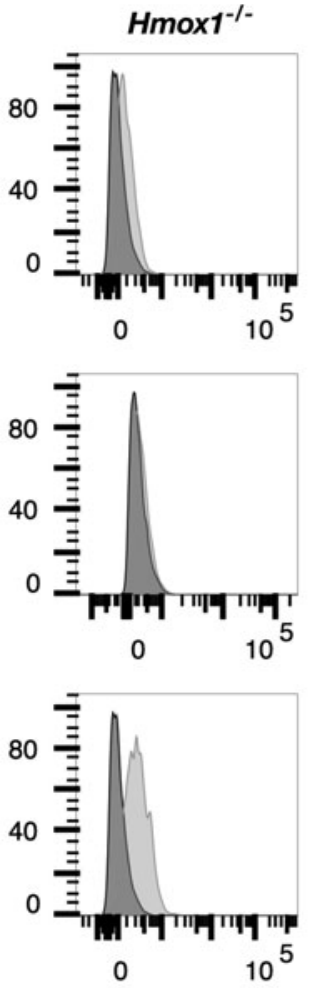

D Sca1+CD140a+CD105+

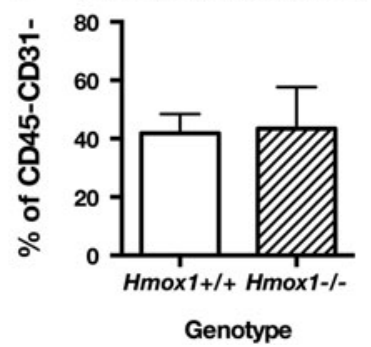

Positive markers
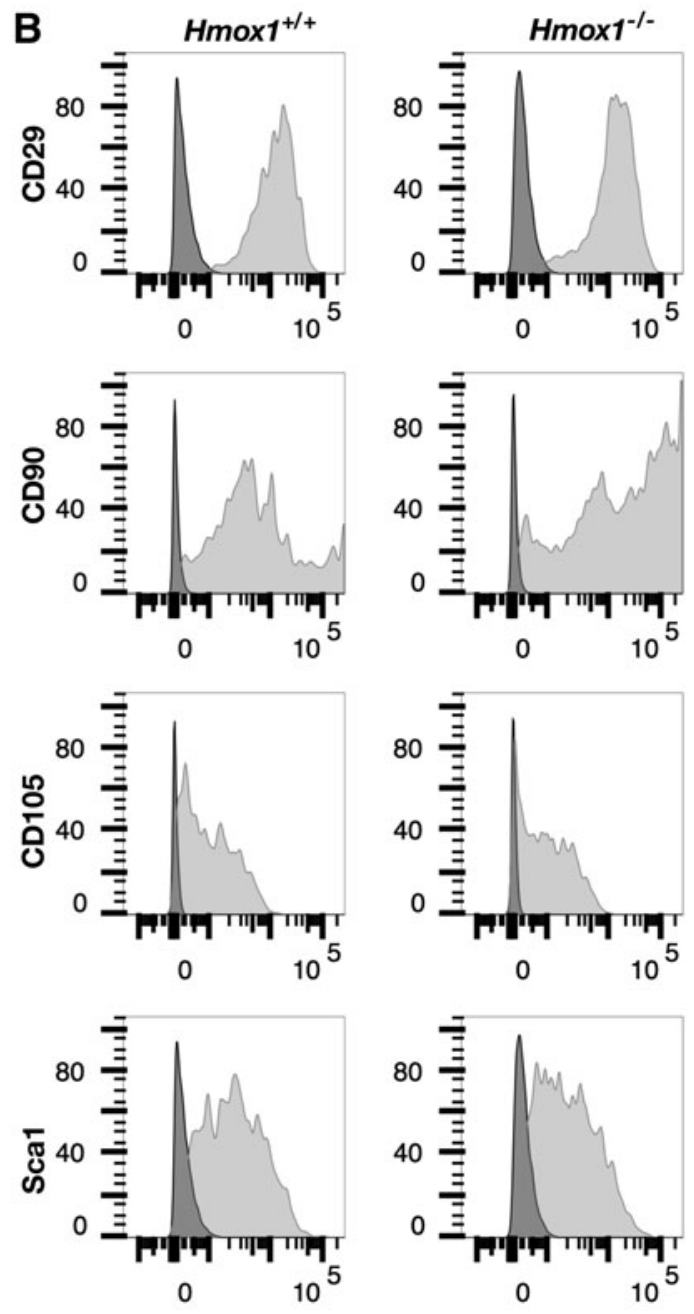

FIG. 1. MSC Hmox1 $1^{+/+}$or Hmox $1^{-/-}$have similar phenotype. Expression of MSC positive markers CD29, CD90, CD105, and Sca-1 (A), MSC negative markers CD31, CD34, and ckit in Hmoxl $1^{+/+}$or Hmoxl $1^{-/-}$MSCs (B). Phenotype of nonsorted bone marrow stromal cells in passage 4: fraction of $\mathrm{CD}^{-} 5^{-} \mathrm{CD} 31^{-}$cells in culture (C), fraction of Sca$1^{+} \mathrm{CD} 140 \mathrm{a}^{+}$cells within $\mathrm{CD} 45^{-} \mathrm{CD} 31^{-}$population $(\mathrm{D})$, or Sca $-1^{+} \mathrm{CD} 140 \mathrm{a}^{+} \mathrm{CD} 105^{+}$cells within $\mathrm{CD} 45^{-} \mathrm{CD} 31^{-}$population in $H_{m o x l} I^{+/+}$or $H_{m o x l} I^{-/-}$cells. (C, D, N=9-10). MSCs, mesenchymal stromal cells.

Fig. S1D). Levels of other tested microRNAs associated with adipogenesis, namely miR-31-5p, miR-150-5p, miR-301a$5 p$, miR-378a-3p, or miR-378a-5p, remained unchanged in cells of both genotypes (Supplementary Fig. S1E-I). Further, basal expression of all tested microRNAs, including miR-21$5 \mathrm{p}$, which increased during adipocyte differentiation only in $H$ mox $1^{+/+}$cells, was similar in MSC Hmox ${ }^{+/+}$and Hmoxl ${ }^{-/-}$ (data not shown).

Effects of changed expression of HMOX1 in human MSCs on the adipogenesis or osteogenesis were stronger when cells were cultured in high glucose concentration (3). Therefore, we tested markers of adipogenesis in MSC Hmoxl ${ }^{+/+}$or Hmox $1^{-/}$differentiated in low or high glucose concentration. Interestingly, adipogenic differentiation of murine bone marrow-derived Hmoxl $1^{+/+}$or $\mathrm{Hmox}^{-/-} \mathrm{MSCs}$ did not change when cells were cultured under high glucose conditions. Both Hmoxl $1^{+/+}$and Hmoxl $1^{-/-}$MSCs upregulated fatty acid-binding protein 4-a marker of adipocyte differentiation (Fig. 2D).

MSCs were shown to be precursors of fibroblasts and myofibroblasts and, therefore, contribute to the tumor stroma (35) or development of fibrosis (30). Heme oxygenase-1 can affect both tumor microenvironment (62) and kidney fibrosis (47). Therefore, we investigated whether the lack of Hmoxl gene in MSCs may influence their ability to form myofibroblasts. Hmox ${ }^{+/+}$and Hmoxl ${ }^{-/-}$MSCs were differentiated to myofibroblasts with TGF $\beta 1$ treatment for 6 days. Cells changed their morphology (Supplementary Fig. S1J) and upregulated $\alpha$-smooth muscle actin (Acta2) (Fig. 2E). Of note, upregulation of Acta2 was lower in myofibroblasts derived from Hmox $^{-/-}$cells.

Transcript levels of fibroblast-specific protein 1 (Fspl) (Fig. 2F) tended to decrease in $H \operatorname{mox} 1^{+/+}$and Hmoxl ${ }^{-1-}$ MSCs; however, this trend reached significance only in 

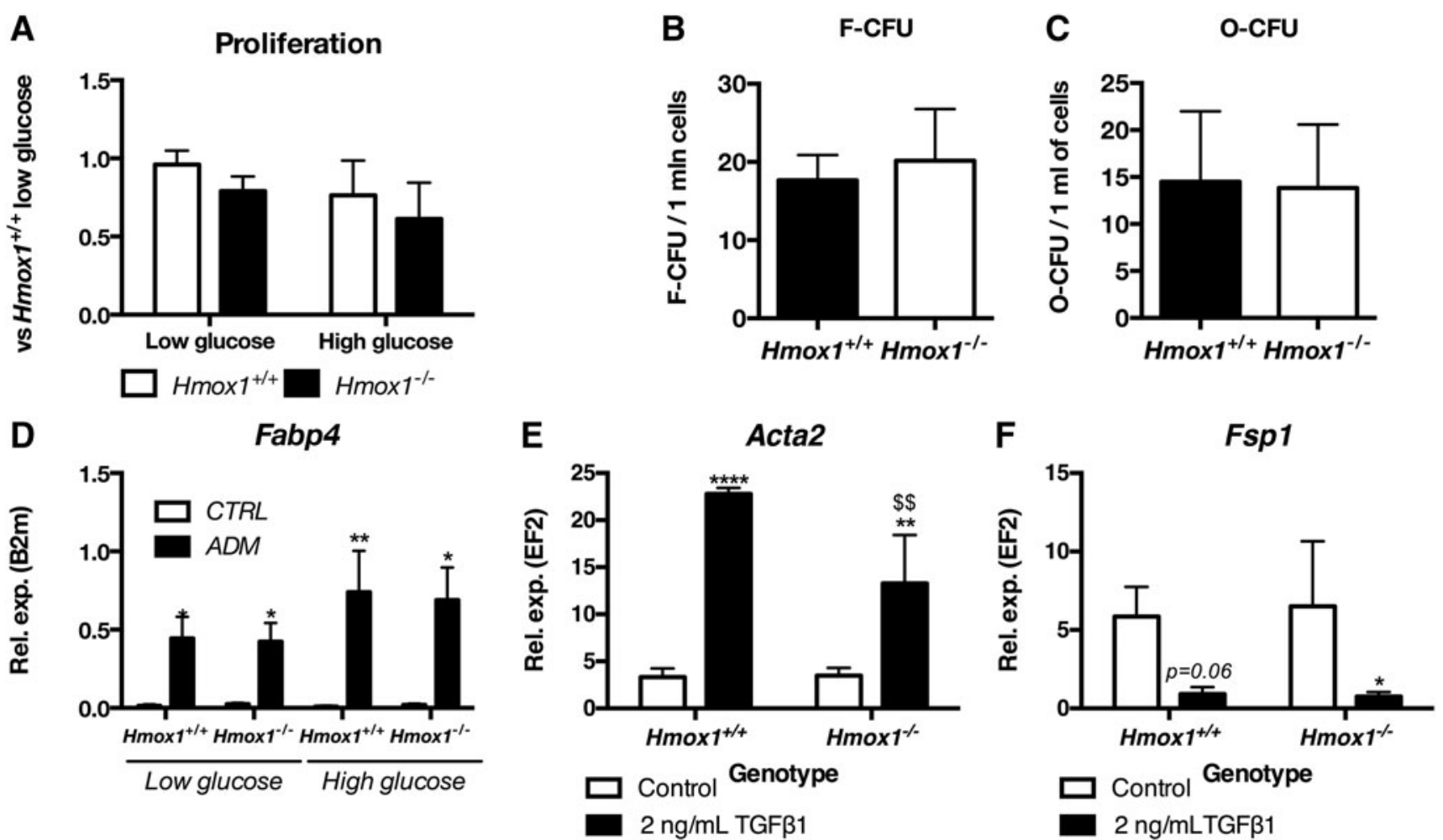

FIG. 2. MSC Hmox1 $1^{+/+}$or Hmox $1^{-/-}$show similar ability to differentiate to adipocytes, osteoblasts and smooth muscle cells. Proliferation of MSC Hmoxl ${ }^{+/+}$or Hmox ${ }^{-/-}$in low or high glucose medium assessed with BrDU assay (A). Ability to form fibroblastoid (B) or osteoblast $(\mathbf{C})$ colonies by bone marrow cells isolated from $H m o x 1^{+/+}$or $H m o x 1^{-/-}$ MSCs assessed with fibroblastoid or osteoblast colony-forming unit assay, respectively. Data shown as mean $+\mathrm{SD}, N=3$. Expression of Fabp4 in Hmoxl $1^{+/+}$or Hmox $1^{-/}$MSCs differentiated to adipocytes in low or high glucose conditions (D) Gene expression was assessed with qRT-PCR. Data are shown as mean $+\mathrm{SD}, N=4-7$. Expression of Acta2 (E), Fspl (F) measured with qRT-PCR in control and differentiated MSC Hmoxl ${ }^{+/+}$or Hmoxl ${ }^{-/}$. Data are shown as mean \pm SD, $* p<0.05, * * p<0.01, * * * * p<0.0001$ control versus TGFb1; ${ }^{\$} p<0.01 \mathrm{Hmox} 1^{+/+}$versus Hmox $1^{-/-}, N=3$. $\mathrm{qRT}-\mathrm{PCR}$, quantitative real-time PCR.

Hmox $1^{-/-}$cells. To summarize, we show here that MSCs, regardless of the heme oxygenase-1, show similar phenotype and differentiation ability, even in stress conditions.

\section{Lack of Hmox1 does not change MSCs immunomodulatory activity or production of cytokines}

Akiyama et al. showed that MSCs injected intravenously can decrease numbers of circulating $\mathrm{CD}^{+}$and increase $\mathrm{T}$ cell apoptosis (1). Mougiakakos et al. suggested that inhibition of HO1 activity can decrease MSCs ability to induce $\mathrm{T}$ regulatory cells (37). Therefore, to test the effect of complete knock-out of Hmoxl on immunomodulatory activity of MSCs, we in-

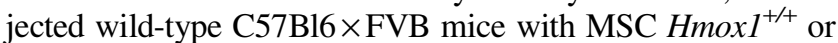
$\left.H_{m o x}\right]^{-/}$and analyzed apoptosis and activation of T cells.

Numbers of circulating $\mathrm{CD}^{+} \mathrm{T}$ cells did not change in mice injected with MSCs (Fig. 3A). However, numbers of apoptotic Annexin $\mathrm{V}^{+} \mathrm{CD}^{+}$cells tended to increase after the MSC injection, but this trend did not reach statistical significance (Fig. 3B). Injection of MSC Hmoxl ${ }^{+/+}$or Hmoxl ${ }^{-/-}$did not affect the numbers as well of activated $\mathrm{CD} 3{ }^{+} \mathrm{CD} 4^{+} \mathrm{CD} 25^{\text {high }} \mathrm{T}$ cells (Fig. 3C). In vitro, primary murine $\mathrm{CD}^{+} \mathrm{T}$ cells cocultured with MSC Hmoxl $1^{+/+}$or Hmoxl $^{-/-}$showed a similar cell cycle (Supplementary Fig. S2A-C), percentage of $\mathrm{Ki}^{+} 7^{+}$ cells (Supplementary Fig. S2D) and annexin $\mathrm{V}^{+}$cells (Supplementary Fig. S2E).
Further, lack of the functional Hmoxl gene did not change the profile of cytokines and growth factors produced by MSC. Conditioned media from MSC Hmoxl ${ }^{+/+}$and Hmoxl $1^{-/-}$ contained similar amounts of G-CSF, IL-6, LIF, LIX, CXCL1, CXCL2, CCL5, and VEGF (Fig. 3D-K). Levels of eotaxin, GM-CSF, IGN $\gamma$, IL- $1 \alpha$, IL- $1 \beta$, IL-2, IL-3, IL-4, IL5, IL-7, IL-9, IL-10, IL-12 p40, IL-12 p70, IL-13, IL-15, IL17, MIP- $1 \alpha$, MIP-1 $\beta$, M-CSF, MIP-2, MIG, and TNF $\alpha$ were under the threshold of detection. Therefore, we concluded that lack of the Hmoxl gene did not change the tested MSC secretome and did not affect the ability of MSCs to induce T cell death both in vitro and in vivo.

\section{$\mathrm{Hmox}^{+/+}$and Hmox $1^{-/}$MSCs show high resistance to oxidative stress induced with $\mathrm{H}_{2} \mathrm{O}_{2}$ or hemin}

Bone marrow-derived proangiogenic cells (BDMC) lacking Hmoxl gene were characterized by higher sensitivity to oxidative stress, that is, induced with hemin (16). Therefore, we decided to test whether it is also true for MSCs. Surprisingly, Hmoxl $1^{+/+}$and Hmox1 $1^{-/-}$MSCs showed no difference in the viability when treated for $6 \mathrm{~h}$ with $\mathrm{H}_{2} \mathrm{O}_{2}$ or $50 \mu \mathrm{mol} / \mathrm{L}$ hemin in both low and high glucose conditions (Fig. 4A, B). Moreover, treatment with $10 \mathrm{ng} / \mu \mathrm{l}$ of $\mathrm{TNF} \alpha$ for $24 \mathrm{~h}$ did not yield significant differences in the viability of MSCs with or without Hmoxl (Supplementary Fig. S3A, B). 
A $\quad$ CD3 $^{+}$

B

CD3 $^{+}$Annexin $\mathrm{V}^{+}$

C

CD4 ${ }^{+} \mathrm{CD} 25^{\text {high }}$
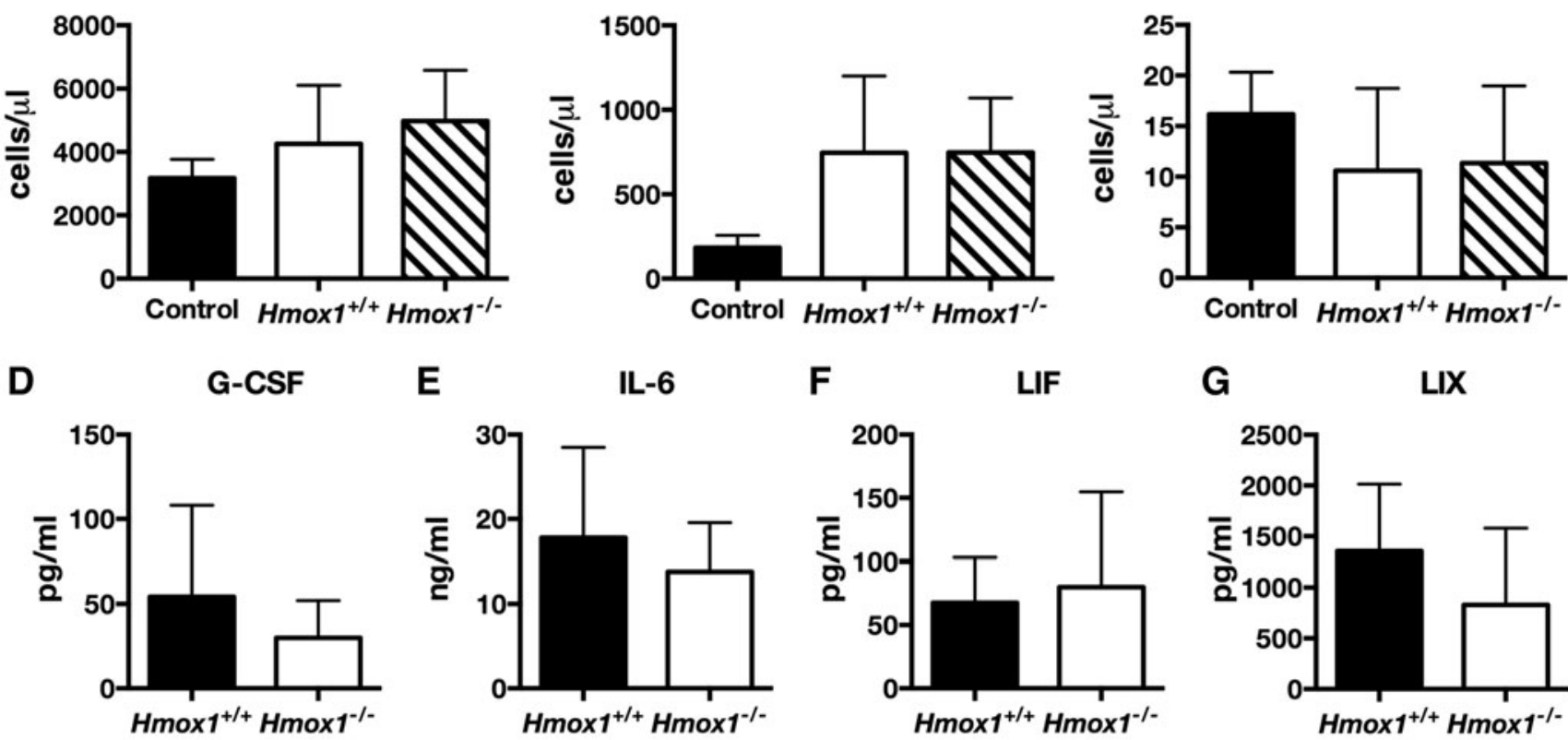

E IL-6

L-6 F

F LIF

G

니X
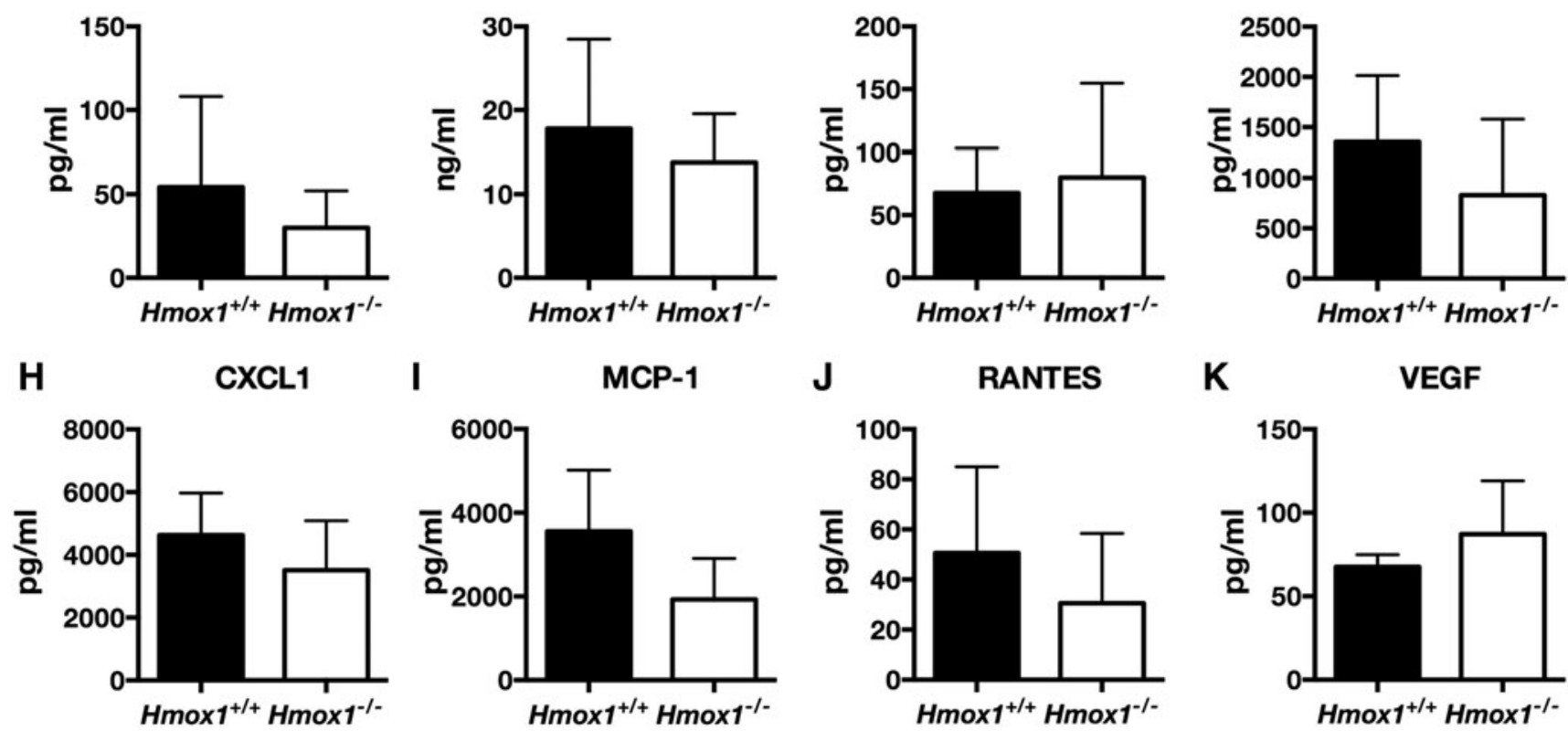

FIG. 3. Lack of Hmox1 in MSC does not affect their immunomodulatory properties or secretory profile. Number of circulating $\mathrm{CD}^{+} \mathrm{T}$ cells $(\mathbf{A}), \mathrm{CD}^{+}$Annexin $\mathrm{V}^{+}$apoptotic $\mathrm{T}$ cells $(\mathbf{B})$, or activated $\mathrm{CD} 3^{+} \mathrm{CD} 4^{+} \mathrm{CD} 25^{\text {high }} \mathrm{T}$ cells $(\mathbf{C})$ in control mice or injected i.v. with MSC Hmoxl $1^{+/+}$or $\operatorname{Hmoxl}^{-/}(N=3-4)$. Concentration of G-CSF (D), IL-6 (E), LIF (F), LIX (G), CXCL1 (H), MCP-1 (I), RANTES (J), and VEGF (K) in conditioned media from Hmox $1^{+/+}$or Hmox $1^{-/-}$MSC assessed with multiplex assay on Luminex platform. Data are shown as mean $\pm \mathrm{SD}$, Mann-Whitney, $N=4$.

Subsequently, we checked the toxic concentrations of hemin for MSC Hmoxl ${ }^{+/+}$and Hmoxl $1^{-/}$. Surprisingly, hemin was more toxic for Hmoxl $1^{-/-}$MSCs than for $H_{m o x} 1^{+/+}$cells not until at a concentration of $200 \mu \mathrm{mol} / \mathrm{L}$ (Fig. 4C). However, conditioned media from both MSC $\mathrm{Hmoxl}^{+/+}$and Hmoxl ${ }^{-/-}$ showed similar total antioxidant capacity assessed with total antioxidant capacity (TAC) (Fig. 4D), 2,2'-azino-bis (3-ethylbenzothiazoline-6-sulphonic acid) (ABTS), or ferric-reducing antioxidant power (FRAP) assays (Supplementary Fig. S3C, D). The latter result suggests that the reason for the MSC resistance to oxidative stress is rather intrinsic.

First, we supposed that low sensitivity of Hmoxl ${ }^{+/+}$and Hmox $^{-1-}$ MSCs to hemin, especially in comparison to BDMC, could be related to the high expression of heme oxygenase-2. However, the expression of Hmoxl was lower in MSCs Hmoxl ${ }^{+/+}$than in PACs Hmoxl ${ }^{+/+}$(Fig. 4E). Similarly, the expression of Hmox2 was lower in MSCs than in PAC cells and similar in $H_{m o x} I^{+/+}$and $\left.H_{m o x}\right]^{-/}$cells (Fig. 4F). Then, we hypothesized that low sensitivity of Hmox ${ }^{-/-}$MSC cells could be caused by the low uptake of heme from the culture medium. Therefore, we analyzed heme uptake with two methods-direct measurement of heme in cells stimulated for $2 \mathrm{~h}$ with $50 \mu \mathrm{mol} / \mathrm{L}$ hemin, and then after $2 \mathrm{~h}$ in fresh medium (Fig. 5A), and with the measurement of tin protoporphyrin IX fluorescence.

Hmox $1^{+/+}$and Hmox $I^{-/-}$MSCs displayed comparable levels of cellular heme at all timepoints tested (Fig. 5B). Moreover, both cell genotypes showed comparable SnPP fluorescence proportional to the concentration of $\mathrm{SnPP}$ in the culture medium (Supplementary Fig. S4A). Therefore, higher resistance to hemin in comparison to PAC cannot be explained by the compensation of Hmox 1 function by Hmox 2 or by changed uptake of hemin.

Since bone marrow PACs are mostly of monocytic origin, and therefore distant from MSCs, we decided to further focus on the differences in stress response between MSCs and fibroblasts. Interestingly, mouse tail-tip fibroblasts had a phenotype similar to MSCs, that is, they expressed Sca1, CD106 and part of them showed positive for CD140a (Supplementary Fig. S5). Both fibroblasts and MSCs, regardless of Hmox 1, were characterized by the similar expression of heme transporters Hcpl (Slc46al) and Hrgl (Slc48al) 
A

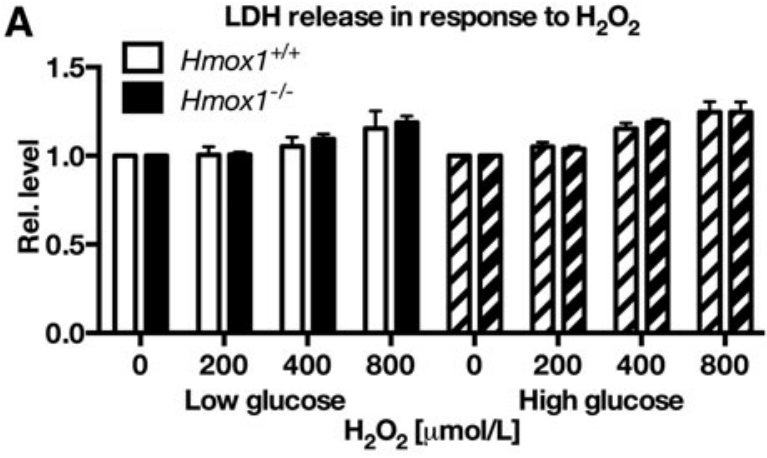

B LDH release in response to hemin

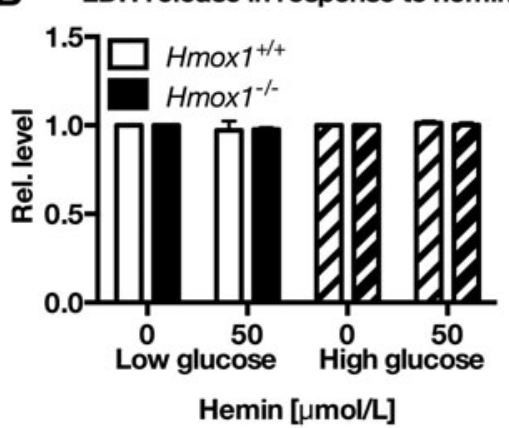

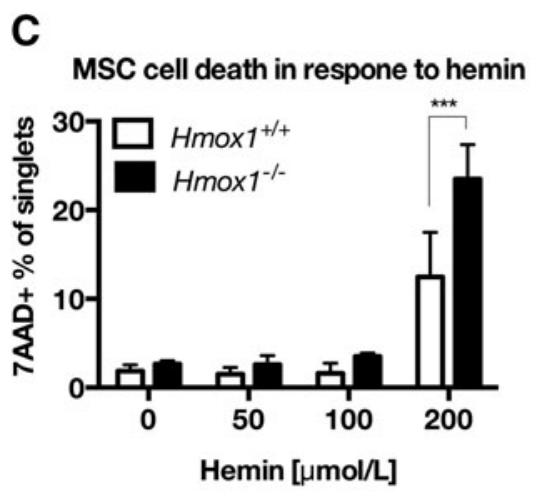
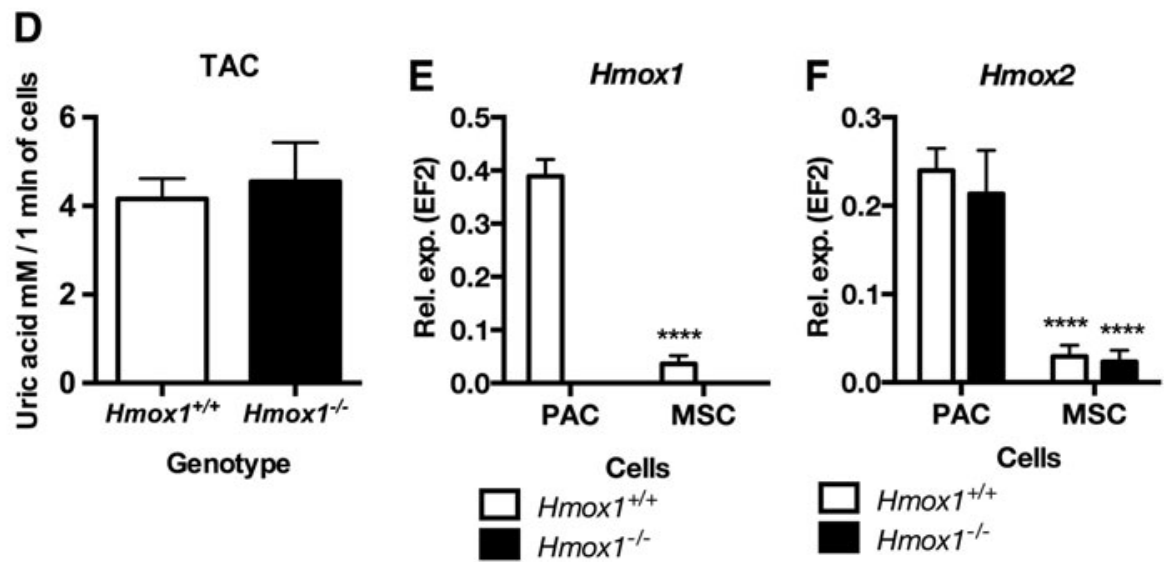

FIG. 4. MSC, regardless of the low expression of both heme oxygenases 1 or 2 , show high resistance to hemin or hydrogen peroxide. $\mathrm{LDH}$ release in MSC Hmoxl ${ }^{+/+}$or $\mathrm{Hmoxl}^{-/-}$treated with $\mathrm{H}_{2} \mathrm{O}_{2}$ (A) or hemin (B) in low or high glucose medium. Cell death in MSC Hmoxl $I^{+/+}$or Hmoxl ${ }^{-/}$treated with increasing concentrations of hemin for $6 \mathrm{~h}$, assessed with 7-AAD staining and flow cytometry $(\mathbf{C})$. Data are shown as mean \pm SD. $* * * p<0.001$ two-way ANOVA with Bonferroni post-test, $N=3$. Total antioxidant capacity of conditioned media from MSC Hmoxl ${ }^{+/+}$or $\mathrm{Hmoxl}^{-/-}$, measured with TAC kit $(N=4)(\mathbf{D})$. (E) Expression of Hmoxl, (F) Hmox2 in murine bone marrow PAC and MSCs isolated from $\mathrm{Hmoxl}^{+/+}$or Hmoxl ${ }^{-/-}$mice, $* * * * p<0.0001 \mathrm{MSC}$ versus PAC; two-way ANOVA with Bonferroni post-test, $N=3$. 7-AAD, 7-aminoactinomycin D; ANOVA, analysis of variance; LDH, lactate dehydrogenase; PAC, pro-angiogenic cell; TAC, total antioxidant capacity.

(Supplementary Fig. S4B, C). MSCs Hmox ${ }^{-/-}$were the only ones to increase in response to hemin treatment and the expression of heme exporter FLVCR1 (Fig. 5C), which may protect them from the heme overload.

To further elucidate the effects of heme on MSCs, we analyzed genes involved in heme synthesis, of which Alasl is regulated by heme. Treatment with hemin $(50 \mu \mathrm{mol} / \mathrm{L})$ decreased Alas 1 expression in all treated cells. Therefore, we concluded that heme in the culture medium enters treated cells regardless of Hmoxl expression and affects known heme-regulated pathways. In Hmox $1^{-1}$ fibroblasts, already control cells were characterized by lower Alas 1 levels than Hmoxl $^{+/+}$cells (Fig. 5D). Expression of Uros in hemintreated $\mathrm{Hmoxl}^{-/-}$fibroblasts was lower than in corresponding MSC cells (Supplementary Fig. S4D).

What is more, Hmoxl ${ }^{-/-}$fibroblasts treated with hemin decreased Cpox expression whereas it remained unchanged in other cell types (Supplementary Fig. S4E). There were no differences in the expression of Hmbs, Alad, Ppox, and Fech (Supplementary Fig. S4E, F). Hmoxl was similarly upregulated in both $\mathrm{Hmoxl}^{+/+}$MSCs and fibroblasts (Fig. 5E). The expression of Hmox 2 was not affected by hemin treatment and did not differ in any of the tested groups of cells (Fig. 5F). To sum up, MSCs Hmoxl ${ }^{-1-}$ show higher resistance to $\mathrm{H}_{2} \mathrm{O}_{2}$ and hemin than previously tested PACs (16). However, low sensitivity to hemin is not caused by changes in heme uptake or synthesis and it is not related to Hmox2.

\section{Hemin increases cellular $\mathrm{H}_{2} \mathrm{O}_{2}$ in $\mathrm{Hmox}^{-1}$} MSCs and fibroblasts

To assess the effects of hemin on oxidative stress in the MSCs $H_{m o x} I^{+/+}$and Hmoxll $I^{-/}$, we analyzed the levels of cellular hydrogen peroxide by using $\mathrm{H}_{2}$ DCFDA staining. Tailtip fibroblasts isolated from the same Hmoxl $I^{+/+}$or Hmoxl ${ }^{-/-}$ mice were used as nonprogenitor internal control cells. After $6 \mathrm{~h}$ of incubation with hemin $(50 \mu \mathrm{mol} / \mathrm{L})$, levels of $\mathrm{H}_{2} \mathrm{O}_{2}$ were increased in $\mathrm{Hmoxl}^{-/-}$MSCs and fibroblasts and higher than in respective wild-type cells (Fig. 5G). After a 24-h incubation period, levels of $\mathrm{H}_{2} \mathrm{O}_{2}$ remained low in $\mathrm{Hmoxl}^{+/+}$cells and were higher in Hmoxl $I^{-/-}$fibroblasts than in $\mathrm{Hmoxl}^{-/-}$MSCs (Fig. 5H). This suggests that murine MSCs might be equipped with an anti-oxidant protective mechanism, which works better than in fibroblasts.

Nevertheless, after $48 \mathrm{~h}$ of stimulation with hemin, both Hmoxl $I^{-/}$MSCs and Hmoxl ${ }^{-/-}$fibroblasts were dead. Interestingly, at this late timepoint, levels of cellular $\mathrm{H}_{2} \mathrm{O}_{2}$ were higher in hemin-treated $\mathrm{Hmoxl}^{+/+}$fibroblasts than in 
A

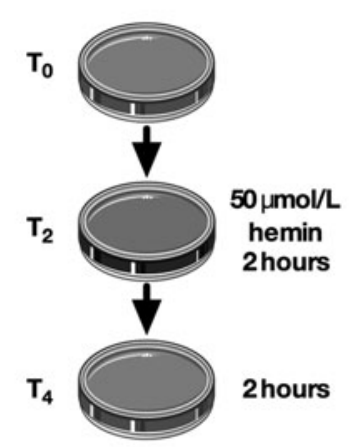

B

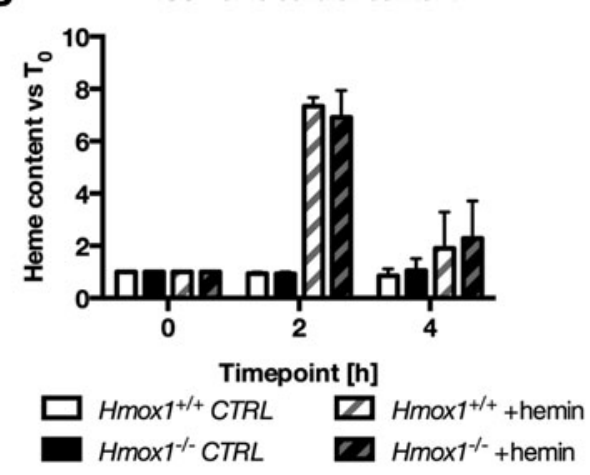

C

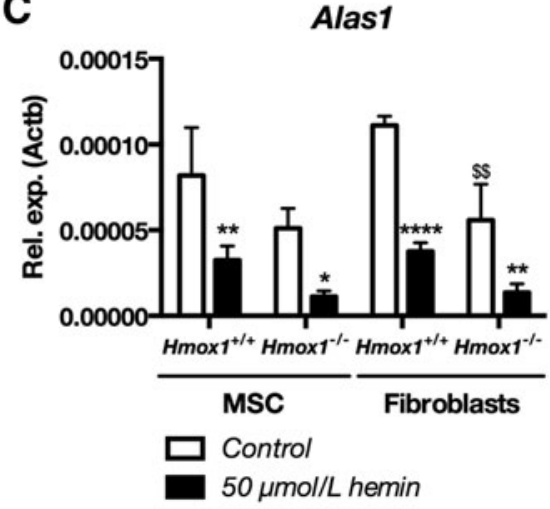

$\mathbf{F}$

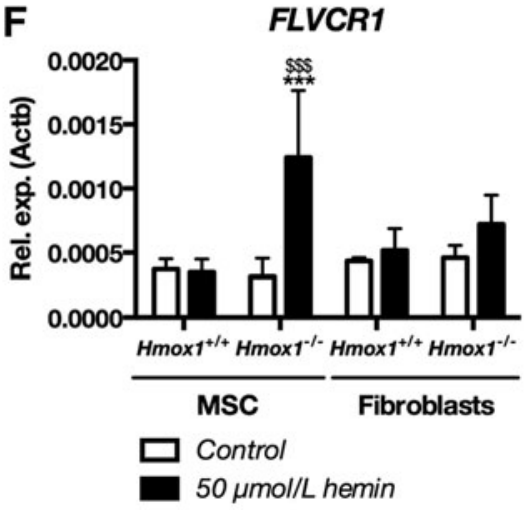

I

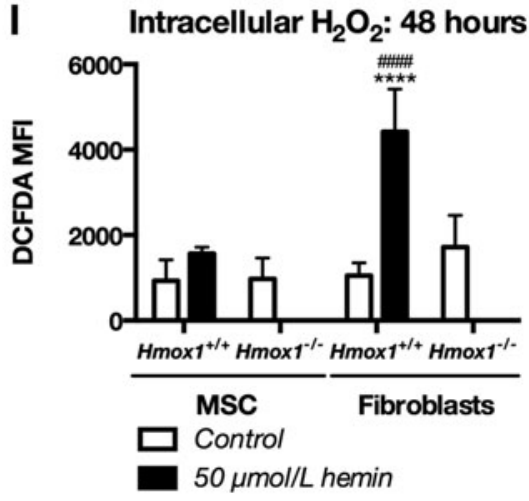

FIG. 5. Hemin increases intracellular hydrogen peroxide in $\mathrm{Hmox}^{+/+}$or $\mathrm{Hmox}^{-/-}$and decreases Alas1 expression but does not affect levels of heme importers. Scheme of the experiment for the assessment of intracellular heme content (A). Heme cellular content measured with spectrophotometry in MSC $\mathrm{Hmoxl}^{+/+}$or $\mathrm{Hmoxl}^{-/-}$stimulated for $2 \mathrm{~h}$ with hemin $\left(\mathrm{T}_{2}\right)$ and then after $2 \mathrm{~h}$ in hemin-free medium $\left(\mathrm{T}_{4}\right), N=3(\mathbf{B})$. Expression of FLVCRI (C), Alas1 (D), Hmoxl (E), and Hmox2 $(\mathbf{F})$ in Hmoxl $I^{+/+}$or Hmoxl ${ }^{-/-}$MSCs or fibroblasts stimulated for $6 \mathrm{~h}$ with $50 \mu \mathrm{mol} / \mathrm{L}$ hemin. Levels of $\mathrm{H}_{2} \mathrm{O}_{2}$ measured with $\mathrm{H}_{2}$ DCFDA after $6(\mathbf{G}), 24(\mathbf{H})$, or $48 \mathrm{~h}(\mathbf{I})$ in $H$ moxl $I^{+/+}$or $H \operatorname{mox} I^{-/-}$MSCs or fibroblasts stimulated with hemin $(50 \mu \mathrm{mol} / \mathrm{L})$. Data are shown as mean $\pm \mathrm{SD}, * p<0.05, * * p<0.01, * * * p<0.001, * * * * p<0.0001$ hemin-treated cells versus control; ${ }^{\#} p<0.01,{ }^{\# \# \#} p<0.0001$ MSC versus fibroblasts, ${ }^{\$} p<0.05,{ }^{\$ \$} p<0.01,{ }^{\$ \$ \$} p<0.001,{ }^{\$ \$ \$} p<0.0001 \mathrm{Hmox}^{1 /+}$ versus Hmox $1^{-1-}$. Two-way ANOVA with Bonferroni post-test, $N=3$.

HmoxI $I^{+/+}$MSCs (Fig. 5I). Therefore, we concluded that both Hmoxl $^{+/+}$and HmoxI $I^{-/}$MSC cells showed higher resistance to hemin than respective tail-tip fibroblasts.

\section{MSCs lacking Hmox1 efficiently induce antioxidant gene response}

A lower concentration of $\mathrm{H}_{2} \mathrm{O}_{2}$ in MSC Hmoxl ${ }^{-/}$than Hmoxl ${ }^{-/-}$fibroblasts after short incubation with hemin sug- gested that MSCs might more effectively respond to the prooxidative insult. Therefore, we evaluated the expression of a vast panel of antioxidant genes in MSCs and $\mathrm{Hmoxl}^{+/+}$or $H$ moxl $I^{-/}$fibroblasts in response to $50 \mu \mathrm{mol} / \mathrm{L}$ hemin. Treatment with hemin did not change the expression of the major regulator of antioxidant gene response Nfe2l2 (Fig. 6A), which encodes for the Nrf2 transcription factor. Levels of Sqstml, which is both target and regulator of $\mathrm{Nrf} 2$ (21), were increased in MSCs and Hmoxl $I^{--}$fibroblasts but the upregulation was higher in MSCs (Fig. 6B). 
A
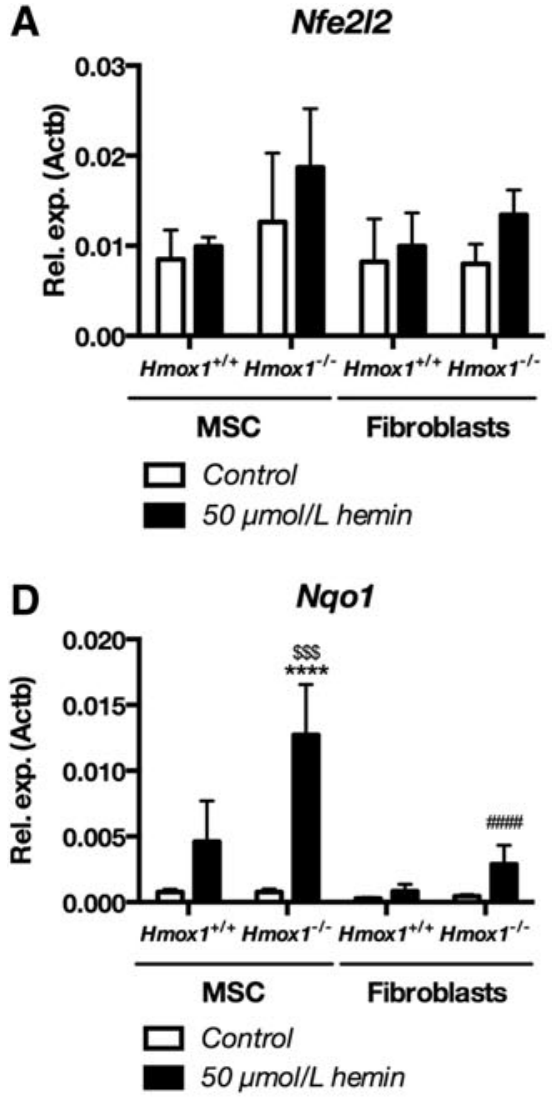

G

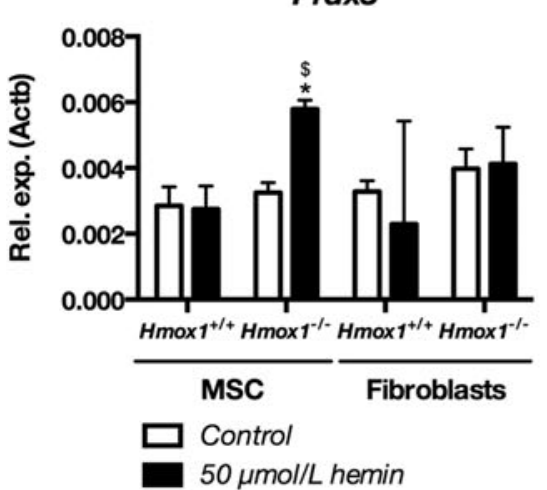

B

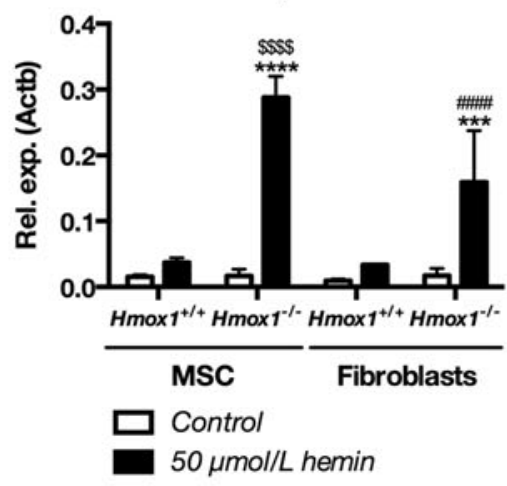

E

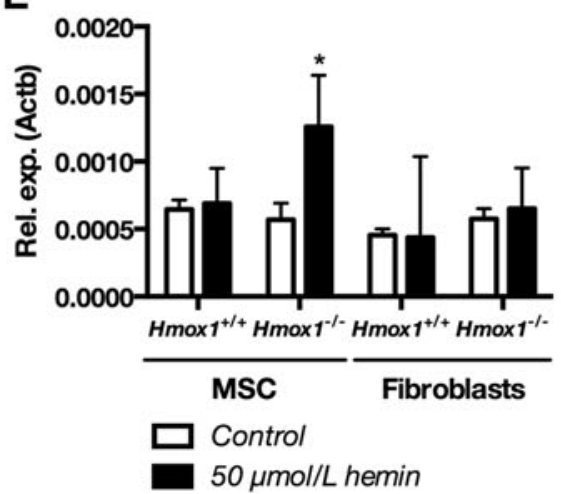

H

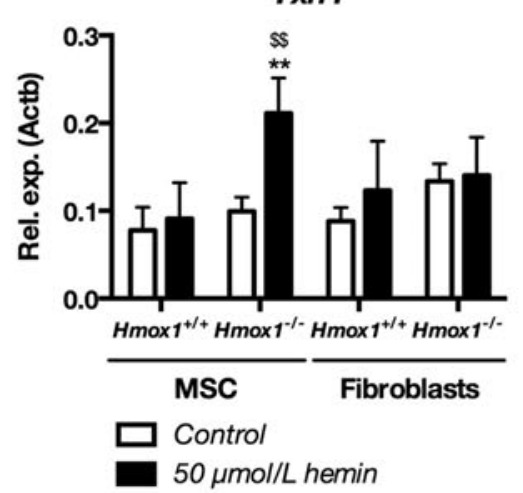

C

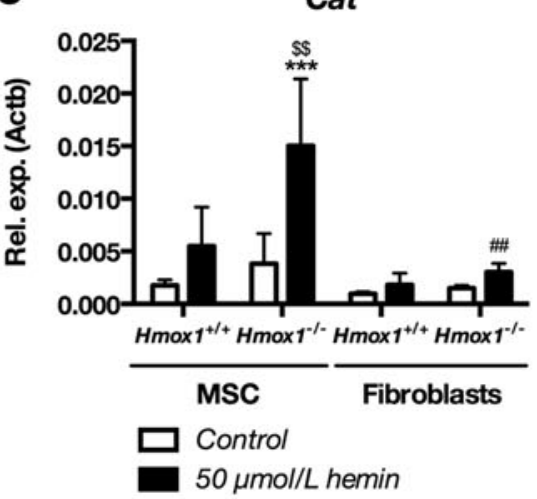

$\mathbf{F}$
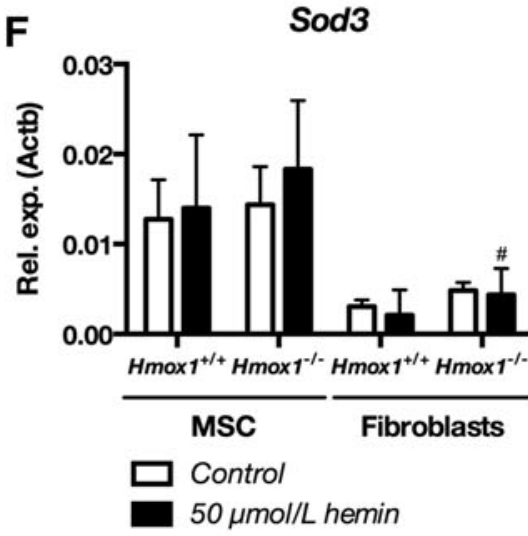

I

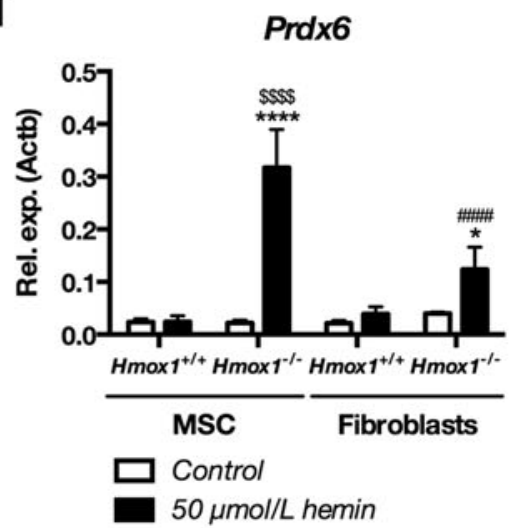

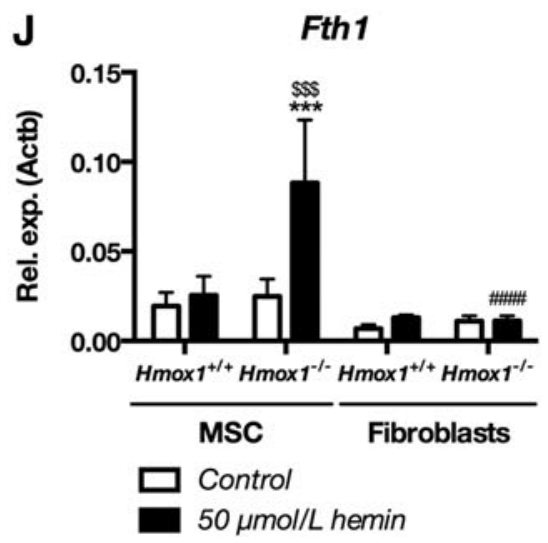

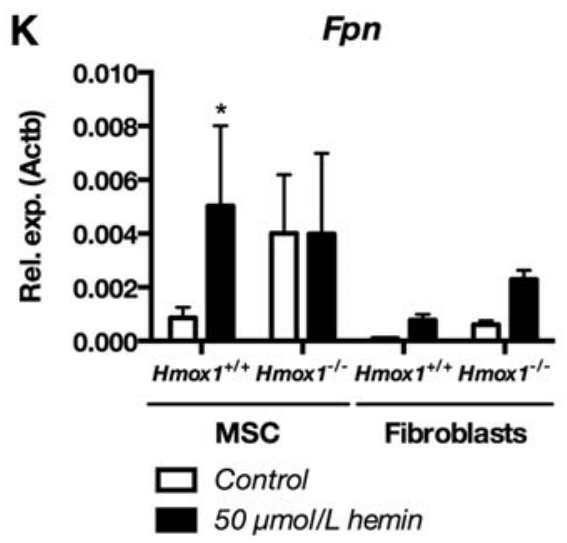

FIG. 6. MSC Hmoxi ${ }^{+/+}$show more efficient antioxidant response after treatment with hemin than fibroblasts Hmox1 $^{+/+}$. Expression of Nfe2l2 (A), Sqstml (B), Cat (C), Nqol (D), Sod2 (E), Sod3 (F), Prdx3 (G), Txn1 (H), Prdx6 (I), Fthl $(\mathbf{J})$, and $F p n(\mathbf{K})$ in $H_{m o x} I^{+/}$or Hmoxl $I^{-/}$MSCs or fibroblasts stimulated for $6 \mathrm{~h}$ with hemin $(50 \mu \mathrm{mol} / \mathrm{L})$. Data are shown as mean \pm SD, ${ }^{*} p<0.05,{ }^{* *} p<0.01, * * * p<0.001,{ }^{* * * *} p<0.0001$ hemin-treated cells versus control; ${ }^{*} p<0.05$, ${ }^{*} p<0.01$, $\mathrm{HWH}_{p}<0.0001 \mathrm{MSC}$ versus fibroblasts, ${ }^{\$} p<0.05,{ }^{\$} p<0.01,{ }^{\$ \$} p<0.001,{ }^{\$ \$ \$} p<0.0001 \mathrm{Hmox}^{+/+}$versus Hmox $1^{-f-}$, Twoway ANOVA with Bonferroni post-test, $N=3$. 
Expression of Cat was the highest in hemin-treated MSC $H$ mox $1^{-/}$, the only ones to change Cat levels (Fig. 6C). Then, Hmox $1^{-/}$fibroblasts treated with hemin had lower expression of Nqol than Hmox1 ${ }^{-/-}$MSCs, the only cells to upregulate $\mathrm{Nqol}$ and with its expression higher than Hmoxl ${ }^{+/+}$ MSCs (Fig. 6D). Similarly, expression of $\operatorname{Sod} 2$ was changed only in Hmox1 $1^{-/-}$MSC (Fig. 6E) whereas hemin-treated Hmox $^{-1-}$ fibroblasts had lower Sod3 levels than corresponding MSC cells (Fig. 6F).

Further, expression of $\operatorname{Prdx} 3$ and $T x n 1$ was enhanced with hemin only in $\mathrm{Hmoxl}^{-/-}$MSC cells (Fig. 6G, H); whereas $\operatorname{Prdx} 4$, Prdx5, and Txnrd3 were not affected (Supplementary Fig. S6A-C). Interestingly, $\operatorname{Prdx6}$, the only 1-Cys member of peroxiredoxin family (13), was potently upregulated in hemintreated Hmox $1^{-/-}$MSCs. Prdx6 expression was then higher in MSC Hmoxl $1^{-/}$than in all other cells (Fig. 6I).

MSCs Hmox $1^{-/-}$were the only ones that upregulated ferritin heavy chain 1 (Fthl) expression in response to the hemin treatment (Fig. 6J). Levels of Fpn were, on the other hand, increased only in Hmox $I^{+/+}$MSCs (Fig. 6K). Hemin did not affect Nox4 expression in any cells (Supplementary Fig. S6D). Interestingly, only Hmox $1^{--}$MSCs decreased Gpxl expression in response to hemin (Supplementary Fig. S6E), whereas expression of Gpx3 and Gpx4 was unchanged (Supplementary Fig. S6F, G), and expression of Gpx8 was decreased in both MSC cell types (Supplementary Fig. S6H). On the other hand, control fibroblasts expressed lower levels of Gpx8 than respective MSCs (Supplementary Fig. S6H).

To summarize, both MSCs and fibroblasts $\mathrm{Hmoxl}^{-/-}$upregulated Sqstm1 and Prdx6 in response to hemin. Moreover, the expression of both genes was higher in treated MSC Hmox $1^{-1-}$ than fibroblasts Hmox $1^{-1-}$. MSC Hmox $I^{-1-}$ but not fibroblasts $H \operatorname{mox} 1^{-/-}$elevated levels of transcripts for Cat, Nqo1, Prdx3, Txn1, and Fth1, which confirmed their more efficient antioxidant response.

Importantly, MSC Hmox $1^{-/-}$were the only cells to potently upregulate quintessential genes involved in the glutathione pathway, namely Gclc, Gclm, Gss, and Gsr. MSC Hmox $1^{-1-}$ also elevated Gstpl (Fig. 7A-E), which forms a heterodimer with Prdx6 (13), also increased in hemintreated MSC Hmox $1^{-/-}$. Levels of Gstk1, another glutathione S-transferase, remained unchanged in all cell types (Fig. 7F). Levels of the upregulated glutathione pathway genes were higher in hemin-treated Hmox $1^{-1-}$ MSC cells than in hemin-treated Hmox $1^{+/+}$MSCs and Hmoxl ${ }^{-/-}$fibroblasts. The latter ones increased expression only of Gclm and Gstpl (Fig. 7B, F).

Finally, to functionally validate the unique influence of hemin on glutathione pathway genes in $H_{m o x} 1^{-/-}$MSCs, we analyzed reduced glutathione (GSH) to oxidized glutathione (GSSG) ratio, changes in total GSH and GSSG in MSCs, and fibroblasts of both $\mathrm{Hmox}^{+/+}$and $H \operatorname{mox} \mathrm{I}^{-/-}$ phenotypes. Cells were treated with hemin $(50 \mu \mathrm{mol} / \mathrm{L})$ for $6 \mathrm{~h}$, like in gene expression experiments. However, we then incubated the cells for two more hours in hemin-free complete medium to allow for GSH recovery. The GSH/ GSSG ratio that allows assessing cellular oxidative stress was decreased in both Hmoxl $1^{+/+}$and Hmoxl $1^{-/-}$MSCs as well as in Hmoxl $^{-1-}$ fibroblasts. Further, Hmoxl ${ }^{-1-}$ fibroblasts were characterized by lower GSH/GSSG ratio than Hmox $1^{-/-}$MSC cells, which additionally had a slightly lower ratio than Hmox $1^{+/+}$MSCs (Fig. 7G).
Noteworthy, Hmoxl ${ }^{-/-}$MSCs were the only ones that increased total GSH in response to hemin, whereas they caused a decrease in total GSH in Hmoxl ${ }^{+/+}$MSCs (Fig. 7H). Levels of GSSG were increased in Hmoxl ${ }^{+/+}$MSCs, Hmox $1^{-/}$MSCs, and $H \operatorname{mox} I^{-1-}$ fibroblasts. They were higher in both $H \operatorname{mox} I^{-1-}$ cell types than in their respective $H \operatorname{mox} 1^{+/+}$counterparts. However, levels of GSSG increased more in $\mathrm{Hmoxl}^{-/}$fibroblasts than in Hmox1 $1^{-/-}$MSCs (Fig. 7I).

MSCs isolated from Hmox $1^{-/-}$mice showed, in comparison to fibroblasts and PAC, higher resistance to hemin. However, hemin still increased cellular concentration of $\mathrm{H}_{2} \mathrm{O}_{2}$ in both MSCs and fibroblasts Hmox $^{-1-}$. We show here for the first time that murine MSCs Hmox $1^{-/}$could better than mouse tail-tip fibroblasts induce antioxidant gene response, especially genes involved in the glutathione pathway. Importantly, changes in the glutathione pathway, observed on the mRNA level, were further validated functionally by the measurement of reduced and oxidized cellular glutathione. One may speculate that such a fast response to stress factors can, in part, contribute to the presence of only minor effects of Hmoxl knockout on other functions of murine bone marrow-derived MSCs.

\section{Discussion}

Murine bone marrow-derived MSCs isolated from Hmox $1^{+/+}$or $H_{m o x} 1^{-/-}$mice showed similar phenotype, proliferation, and differentiation. In our hands, neither proliferation nor differentiation to primary lineages was affected by increased glucose concentrations in the culture media. However, we show here for the first time that in comparison to tail-tip fibroblasts, murine MSCs are more efficient in antioxidant response.

Available reports on the role of Hmox1 in MSC differentiation are often inconsistent, which may result from the use of cobalt or tin protoporphyrins to modulate Hmox1 activity or differences between mouse and human MSCs. Such species-dependent variations were reported, for example, for immunomodulatory activities of MSCs, which are regulated by nitric oxide synthase in murine cells and indoleamine-2,3dioxygenase in human cells (51). We performed our experiments on murine bone marrow-derived MSCs isolated from wild-type or $H$ mox $1^{-/-}$mice. Importantly, the unaffected phenotype of Hmox $1^{-/-}$MSCs as well as no changes in the differentiation to adipocytes, osteoblasts, and chondrocytes were previously shown by Zarjou et al. (66), who also used cells isolated from $H$ moxl $1^{-/}$mice.

On the other hand, Barbagallo et al. reported that expression of heme oxygenase-1 changes during the differentiation of human MSCs to osteoblasts (3) and treatment with osteogenic growth peptide increases HMOX1 expression in human bone marrow MSCs (56). Moreover, human MSCs stimulated with CoPP during the osteogenic differentiation had upregulated osteonectin, osteogenic growth peptide, and osteocalcin. CoPP decreased adipogenic differentiation of MSCs (3, 56), whereas downregulation of HMOX1 with siRNA resulted in enhanced adipogenesis.

Human bone marrow MSCs treated with epoxyeicosatrienoic acid displayed decreased levels of Bach1, a repressor of $H M O X 1$ expression (52), and increased HMOX1 mRNA; whereas levels of $\operatorname{PPAR} \gamma$ and $\mathrm{C} / \mathrm{EBP} \alpha$, involved in adipogenesis, were decreased (57). Vanella et al. reported later on 

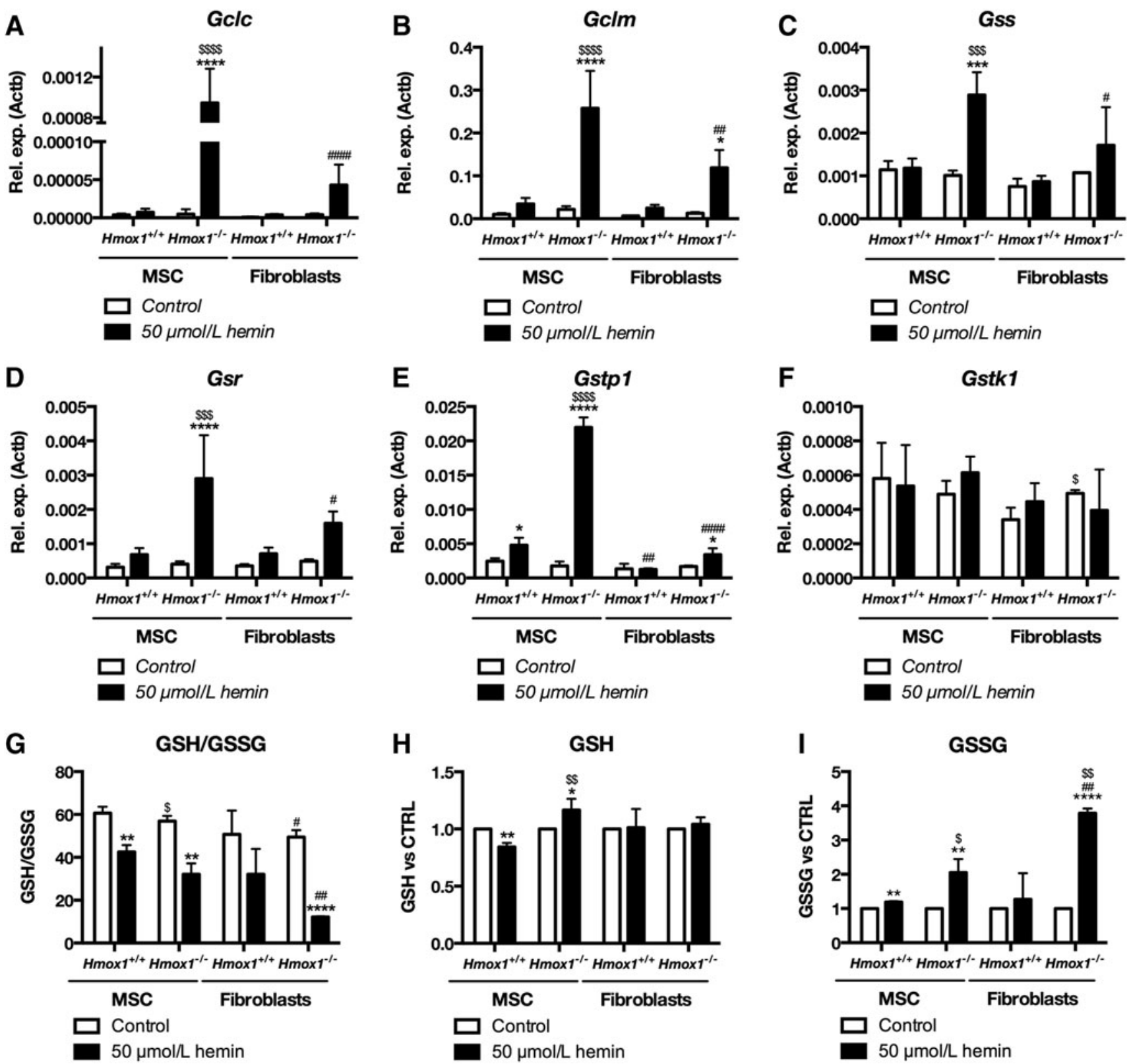

FIG. 7. MSC Hmox $1^{+/+}$strongly induce expression of glutathione pathway enzymes and increase GSH levels after stimulation with hemin. Expression of Gclc (A), Gclm (B), Gss (C), Gsr (D), Gstpl (E), and Gstkl (F) in Hmoxl ${ }^{+/+}$or Hmoxl ${ }^{-/}$MSCs or fibroblasts stimulated for $6 \mathrm{~h}$ with hemin $(50 \mu \mathrm{mol} / \mathrm{L})$. Ratio of GSH to GSSG (G), changes in total GSH $(\mathbf{H})$, and GSSG (I) in $\mathrm{Hmoxl}^{+/+}$or Hmoxl ${ }^{-/-}$MSCs and fibroblasts stimulated for $6 \mathrm{~h}$ with hemin $(50 \mu \mathrm{mol} / \mathrm{L})$ and then kept in fresh medium for $2 \mathrm{~h}$. Levels of GSH and GSSG were measured with GSH/GSSG-Glo ${ }^{\mathrm{TM}}$ Assay. Data are shown as mean \pm SD,

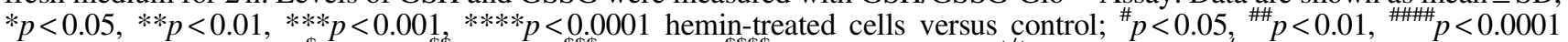
MSC versus fibroblasts, ${ }^{\$} p<0.05,{ }^{\$ \$} p<0.01,{ }^{\$ \$} p<0.001,{ }^{\$ \$ \$} p<0.0001 \mathrm{Hmox}^{+/+}$versus Hmox $1^{-1-}$, Two-way ANOVA with Bonferroni post-test, $N=3$. GSH, reduced glutathione; GSSG, oxidized glutathione.

that inhibition of adipogenesis induced with CoPP and increase with tin mesoporphyrin could be linked to modulation of the canonical Wnt signaling (59).

Use of hemin, heme oxygenase-1 substrate, and potent inductor led to the opposite conclusions. Hemin increased adipogenesis in murine 3T3L1 preadipocytes and human bone marrow MSCs but also increased oxidative stress and induced DNA damage in murine preadipocytes (43). Importantly, all observed changes in gene expression induced with hemin could be reversed with antioxidant Tempol. Therefore, the authors concluded that oxidative stress is the key factor that regulates differentiation patterns in hemintreated cells (43). Human bone marrow MSCs transduced with adenoviral vectors encoding for Hmoxl showed no changes in differentiation pattern but improved viability in hypoxia $(18,68)$. However, adenoviral vectors give only transient expression of the transgene, which was lost after 2 weeks of culture (18).

Primary rat osteoblasts showed reduced expression and activity of alkaline phosphatase and reduced osteocalcin and Runx2 expression levels when treated with hemin or when transduced with adenoviral vectors harboring the Hmoxl 
gene (32). Similar results were obtained with carbon monoxide releasing molecule CORM-2 or bilirubin or when Hmoxl expression was induced with prostaglandin $\mathrm{J} 2$ (PGJ2). Effects of hemin or PGJ2 could be reversed with heme oxygenase-1 inhibitor zinc protoporphyrin (32).

In another study, calcification of human smooth muscle cells was inhibited when cells were stimulated with heme (65). Importantly, the effect of heme and heme oxygenase-1 was mediated by ferritin (65). In our study, MSCs isolated from $H$ mox $1^{-/}$mice had basal levels of $\mathrm{H}_{2} \mathrm{O}_{2}$ similar to those of wild-type cells and potently elevated Fthl in response to hemin. Further, Hmoxi $1^{-/-}$MSCs could induce an efficient antioxidant response to hemin, which is a strong stress factor for cells lacking heme-degrading enzyme. One may speculate that relatively high resistance to oxidative stress observed in MSC $H m o x l^{--}$can, at least in part, explain the observed lack of differences in the pattern of differentiation to basic lineages.

MSC Hmoxl ${ }^{+/+}$or Hmoxl $I^{-/-}$tended to induce T cell apoptosis when injected in vivo. However, the change did not reach statistical significance. Both previous reports analyzing the role of Hmoxl in immunosuppressive activity of MSCs used SnPP to inhibit Hmox 1 activity $(7,37)$ and human and rat (7) or human MSCs (37) and did not assess T cell apoptosis in vivo. Moreover, an in vivo experiment conducted on the role of Hmoxl in MSCs on the protection from graft rejection lacked the control group of animals treated with SnPP only, without MSCs (7). The role played by Hmoxl in human cells remained ambiguous, since Mougiakakos et al. failed to show the direct relation between Hmoxl levels and immunomodulatory activity of MSCs (37).

Surprisingly, both Hmoxl ${ }^{+/+}$and Hmoxl ${ }^{-/-}$MSCs showed high resistance to $\mathrm{H}_{2} \mathrm{O}_{2}$ or, even more unexpectedly, to hemin, irrespective of the concentration of glucose in the medium. Cells devoid of the heme oxygenase-1, enzymedegrading heme, were up to now shown to be highly sensitive to hemin (16). Free heme is toxic to the cells and increases oxidative stress that may lead to lipid peroxidation, DNA damage, and protein aggregation [reviewed in (28)].

In our study, we show for the first time that MSCs Hmox $1^{-/}$were resistant to hemin concentrations, which potently induced cell death in bone marrow PAC cells (16). Moreover, MSCs $\mathrm{Hmoxl}^{-1}$ expressed lower basal levels of Hmox2 than PAC cells, and Hmox2 remained unaffected by hemin treatment. Subsequently, Hmox2-dependent heme degradation cannot be considered a rescue pathway. Finally, Hmoxl ${ }^{+/+}$MSCs were characterized by lower Hmoxl levels than PAC cells and had similar Hmoxl expression in comparison to fibroblasts.

We hypothesized that high MSC resistance to hemin could result from the low import of free heme. Interestingly, heme uptake in $\mathrm{Hmoxl}^{+/+}$and Hmoxl ${ }^{-/-}$MSCs did not differ. The latter results were mirrored by the expression of Slc46al and Slc48al-heme transporters. Expression of Slc48al was shown, however, to be regulated by Bach1 (61), which represses Hmoxl and responds to increased heme concentration. In our hands, hemin increased expression of heme exporter FLVCRl in Hmoxl ${ }^{-/-}$MSCs but not in $\mathrm{Hmoxl}^{+/+}$ MSCs or fibroblasts, regardless of their genotype. Increased FLVCR1 was previously reported in kidneys of $\mathrm{Hmoxl}^{-/-}$ mice (48). Therefore, we might speculate that an increase in FLVCRI can, at least in part, account for the MSC Hmoxl ${ }^{-1-}$ resistance to hemin.
As expected, hemin decreased expression of 5'aminolevulinate synthase 1 in all tested cell types. Alas1 is a heme synthesis rate-limiting enzyme, whose levels are tightly regulated because of the presence of heme regulatory motif in its promoter (38). Other enzymes involved in the heme synthesis were mostly not changed and did not differ between $\mathrm{HmoxI}^{+/+}$and Hmoxl $I^{-/-}$cells. Regarding the iron metabolism, hemin-treated $\mathrm{Hmoxl}^{+/+}$MSCs upregulated ferroportin. Fpn expression did not change in MSC Hmoxl $I^{-/-}$cells, but they showed a trend toward higher ferroportin levels than wild-type controls. On the other hand, Hmoxl $I^{-1-}$ but not Hmox $I^{+/+}$MSCs or any of fibroblast cells increased ferritin that captures labile iron and, therefore, protects cells from oxidative stress [reviewed in (28)].

Although $6 \mathrm{~h}$ of treatment with $50 \mu \mathrm{mol} / \mathrm{L}$ hemin did not increase cell death in $\mathrm{Hmoxl}^{-1-}$ MSCs, it elevated concentrations of cellular hydrogen peroxide. Levels of $\mathrm{H}_{2} \mathrm{O}_{2}$ were higher in $\mathrm{Hmoxl}^{-/-}$fibroblasts than in $\mathrm{Hmoxl}^{-/-}$MSCs also after $24 \mathrm{~h}$ of treatment with hemin and, importantly, in Hmox $^{+/+}$fibroblasts than in Hmoxl $I^{+/+}$MSCs after 48 of culture. However, neither in fibroblasts nor in MSCs we found any differences in basal levels of $\mathrm{H}_{2} \mathrm{O}_{2}$.

Previously, higher $\mathrm{H}_{2} \mathrm{O}_{2}$ levels were reported in $\mathrm{Hmoxl}^{-/-}$ than in $\mathrm{Hmoxl}^{+++}$iPS cells (31). Increased protein carbonylation and lipid peroxidation were also reported in livers and kidneys of $\mathrm{Hmoxl}^{-/-}$mice (42). Basal intracellular ROS levels in human MSCs and fibroblasts were similar and lower than ROS in INS-1 insulinoma (55). Both MSCs and fibroblasts were characterized by similar levels of SOD1, SOD2, $C A T$, and GPX1 mRNA, and higher activities of catalase and glutathione peroxidase- 1 than in INS- 1 cells (55). Of note, in our study, the concentration of hemin, which was toxic for MSC Hmoxl $1^{-/}$cells, also caused some increase in cell death in $\operatorname{Hmoxl}^{+/+}$MSCs.

MSCs $\mathrm{Hmoxl}^{-/}$upregulated in response to hemin a set of genes involved in antioxidant defense, namely $\operatorname{Sod} 2 \operatorname{Prdx} 3$, Prdx6, Cat, Gclc, Gclm, Gss, Gsr, and Gstpl, all of which can be regulated by the Nrf2 transcription factor. Notably, hemin induced expression of enzymes involved in both synthesis and metabolism of glutathione. Bilirubin, which is rapidly formed by biliverdin reductase from biliverdin, a product of heme oxygenase activity, is a strong antioxidant (50) that has properties that are complementary to glutathione (46). Although glutathione has a much higher cellular concentration than bilirubin, it protects mainly hydrophilic proteins. On the other hand, lipophilic bilirubin can protect lipids. However, in our hands, MSC Hmoxl ${ }^{-/}$cells devoid of heme oxygenase-1 did not change the expression of heme oxygenase-2, another source of cellular biliverdin.

Increased expression of $\gamma$-glytamylcysteine ligase and glutathione synthetase leads to enhanced production of glutathione, whereas upregulated glutathione reductase restores GSH from GSSG. In our experimental setting, GSH to GSSG ratio, which is an indication of cell redox status, decreased in all tested cells treated with hemin. However, the decrease was

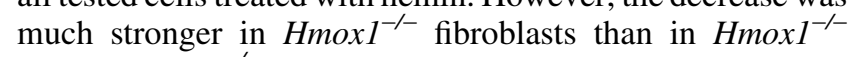
MSCs. Hmoxl ${ }^{-/-}$fibroblasts were characterized by higher total GSSG levels, whereas Hmoxl ${ }^{-/-}$MSCs were the only to increase total GSH.

Of note, HUVEC cells with long alleles of the HMOXI promoter, and thus lower levels of $\mathrm{HMOX1}$, treated with $\mathrm{H}_{2} \mathrm{O}_{2}$ had higher concentrations of total glutathione and GSSG, but 
lower GSH/GSSG ratio than cells with the short promoter (53). Further, hemin was shown to induce neuronal necroptosis, which was related to depletion of glutathione (29).

Increased expression of glutathione metabolism genes in Hmox $1^{-/-}$MSCs was accompanied by the upregulation of peroxiredoxin-6. Prdx6 is the only 1-Cys peroxiredoxin that uses glutathione instead of thioredoxin, and works as a heterodimer with glutathione S-transferase $\pi$ [reviewed in (13)], which was also upregulated in hemin-treated MSC Hmox ${ }^{-1-}$. Peroxiredoxin-6 has double activity: peroxidase and phospholipase $A_{2}$ (13). Interestingly, slightly higher levels of peroxiredoxin 6 were reported in human MSCs than in embryonic stem cells (22) and both peroxiredoxin-6 and glutathione S-transferase $\pi$ but also peroxiredoxins 1 and 2 were highly abundant in human MSCs (60).

Expression of peroxiredoxin-6 was not changed in late passage MSCs in comparison to early passage MSCs, although aged and more senescent cells showed increased $\mathrm{H}_{2} \mathrm{O}_{2}$ concentration (19). In another study, aged MSCs were characterized rather by increased peroxiredoxin 5 expression (24). Surprisingly, hemin treatment, which is used to induce erythroid differentiation of K562 erythroleukemia cells, decreased peroxiredoxin-6 levels in K562 cells (25).

We put forward that increased expression of peroxiredoxin 6 and other antioxidant genes should be rather considered as a protective mechanism that allows cells to deal better with oxidative stress than BDMC (Supplementary Fig. S7). Although levels of $\mathrm{H}_{2} \mathrm{O}_{2}$ in fibroblasts and MSCs were similar, only the latter cells were able to upregulate peroxiredoxin 6 and its partner-glutathione S-transferase $\pi$.

MSCs isolated from Hmox $1^{-/-}$mice were able to react to oxidative stress better than fibroblasts and recovered glutathione faster. One may speculate that MSCs can express lower levels of Keap1 or Nrf3, both of which can decrease activity of Nrf2 transcription factor. Nevertheless, our data show that cells such as MSCs are better equipped with the measures to deal with harsh conditions than other bone marrow-derived cells, especially proangiogenic cells. Further, we can speculate that certain cell types are less dependent on heme oxygenase-1, which is considered a crucial cytoprotective enzyme. Tested functions and differentiation potential of murine MSCs were mostly unaffected by the lack of Hmox1.

\section{Materials and Methods}

\section{Animals}

All procedures involving the use of animals were performed according to approved guidelines. Mice were maintained under the specific pathogen-free conditions, in individually ventilated cages, with full access to food and water. All animal experiments were approved by the Local Ethical Committee for Animal Research at the Jagiellonian University.

\section{Isolation of MSCS}

MSCs were isolated from femurs and tibia of $\mathrm{C} 57 \mathrm{~B} 16 \times \mathrm{FVB}$ Hmox $^{+/+}$or C57B16 $\times \mathrm{FVB} \mathrm{Hmoxl}^{-/-}$. Mice were sacrificed with the overdose of ketamine/xylazine. Bones were resected under the sterile laminar flow hood and cut into small pieces (ca. $1 \mathrm{~mm}^{2}$ ) with a bone cutter. Then, bone chips were digested with $1 \mathrm{mg} / \mathrm{mL}$ type II collagenase (Gibco) for 90-120 $\mathrm{min}$ in $37^{\circ} \mathrm{C}$ in a rotary shaker $(250 \mathrm{rpm})$. Released cells were washed once with PBS and resuspended in the growth medium [ $\alpha \mathrm{MEM}$ supplemented with 10\% FBS (Lonza) and penicillin with streptomycin (Sigma-Aldrich, St. Louis, MO)].

Cells were seeded in six-well plates-bone marrow from one mouse per well. The medium was changed every $24 \mathrm{~h}$ in the first 3 days and every 2-3 days after that, and cells were passaged when confluent. Importantly, before the MACS sorting, cells were detached with short treatment with trypsin ( 2 min; Gibco) at room temperature to decrease the number of highly adherent macrophages in culture. After three passages, MSCs were further purified from the CD $45^{+}$fraction with MACS sorting.

\section{MACS sorting of CD45 murine bone marrow stromal cells}

Bone marrow-derived cells were detached with trypsin, washed with PBS, resuspended in AutoMACS running buffer (Miltenyi), and stained for $25 \mathrm{~min}$ with anti-mouse CD45 MicroBeads (Miltenyi) in $4^{\circ} \mathrm{C}$. Then, the cells were washed with $1 \mathrm{~mL}$ of PBS, resuspended in AutoMACS Running Buffer, and separated on MACS MS columns (Miltenyi) or with AutoMACS (Miltenyi). Flow-through with CD45 ${ }^{-}$cells was collected, and columns with $\mathrm{CD} 45^{+}$cells were discarded. Purified $\mathrm{CD}^{-} 5^{-}$murine bone marrow MSCs were next counted and either used directly for the experiments or seeded for further culture $\left(1.5-2.0 \times 10^{4} / 1 \mathrm{~cm}^{2}\right)$ in $\alpha \mathrm{MEM}$ complete medium (CM).

\section{Isolation of murine fibroblasts}

Murine adult tail fibroblasts were isolated from C57B16 $\times$ FVB Hmox $1^{+/+}$or C57Bl6 $\times$FVB Hmox $1^{-/-}$according to the previously published protocol (49) and cultured in DMEM (Lonza) medium supplemented with 10\% FBS (Lonza) and penicillin with streptomycin (Sigma-Aldrich).

\section{Isolation of murine bone marrow PAC}

Murine bone marrow proangiogenic cells were isolated as described earlier $(14,16)$ and cultured in EGM2-MV medium (Lonza) with 10\% FBS and penicillin with streptomycin (Sigma-Aldrich).

\section{Analysis of fibroblast- or osteoblast colony-forming units}

Cells isolated from the bone marrow were counted by using Türck solution (Merck) to lyse red blood cells. Then, $1 \times 10^{6}$ of bone marrow cells were seeded per well in six-well plates. Cells were cultured until colonies of fibroblastoid cells were formed. At that stage, part of the wells was fixed and stained with crystal violet and the colonies of fibroblastoid cells were counted. Another part of the cells was treated with osteogenic differentiation medium for the next 3 weeks, and then cells were stained with Alizarin Red $S$ and positive colonies were counted.

\section{MSCs phenotyping}

MSCs cultured for three passages after the isolation were detached with trypsin, washed with PBS, and stained for 
25 min in AutoMACS Running Buffer at $4^{\circ} \mathrm{C}$ with the following antibodies: anti-mouse CD45 (clone 30F-11; BD Biosciences), anti-mouse CD29 (clone HM $\beta 1-1$; BioLegend), anti-mouse CD31 (clone MEC13.3; BD Biosciences), antimouse CD34 (clone RAM34; BD Biosciences), anti-mouse CD90.2 (clone 30-H12; BioLegend), anti-mouse CD105 (clone MJ7/18; BioLegend), anti-mouse CD117 (c-kit) (clone 2B8; eBioscience), anti-mouse CD140a (clone APA5; eBioscience), and anti-mouse Ly-6A/E (Sca-1) (clone D7; eBioscience). The phenotype of the cells was assessed with BD LSR II or BD LSR Fortessa (Becton Dickinson).

\section{MSCs: differentiation to osteoblasts}

MSCs Hmoxl ${ }^{+/+}$or Hmoxl ${ }^{-/-}$were differentiated to osteoblasts with the protocol by Zhu et al. (69). Briefly, $2.5 \times 10^{4}$ of sorted $\mathrm{CD} 45^{-}$bone marrow stromal cells were seeded per 1 well of 24-well plates. Osteoblast differentiation was induced for 3 weeks with $\alpha \mathrm{MEM} \mathrm{CM}$ supplemented with $0.1 \mu \mathrm{mol} / \mathrm{L}$ dexamethasone, $10 \mathrm{mmol} / \mathrm{L} \beta$-glycerol phosphate, and $50 \mu \mathrm{mol} / \mathrm{L}$ ascorbate-2-phosphate (all from Sigma-Aldrich) and verified with AlizarinRed S staining (Supplementary Fig. S1A), gene expression analysis, and immunofluorescent staining for osteopontin (clone EPR3688; Abcam). Control cells were cultured in $\alpha$ MEM CM. Low glucose differentiation or control medium contained $5 \mathrm{mmol} / \mathrm{L}$ glucose, and high glucose differentiation or control medium contained $33 \mathrm{mmol} / \mathrm{L}$ glucose.

\section{MSCs: differentiation to adipocytes}

MSCs $\mathrm{Hmoxl}^{+/+}$or Hmoxl $\mathrm{I}^{-/-}$were differentiated to adipocytes with the protocol by Zhu et al. (69). Briefly, $2.5 \times 10^{4}$ of sorted $\mathrm{CD} 45^{-}$bone marrow stromal cells were seeded per 1 well of 24-well plates. Adipocyte differentiation was induced for 3 weeks with $\alpha$ MEM CM supplemented with $1.0 \mu \mathrm{mol} / \mathrm{L}$ dexamethasone, $\quad 50 \mu \mathrm{mol} / \mathrm{L} \quad 3$-isobutyl-1-methylxanthine (IBMX), and $10 \mathrm{ng} / \mathrm{mL}$ insulin (all from Sigma-Aldrich) and verified with OilRedO staining, gene expression analysis, and immunofluorescent staining for Fabp4 (clone EPR3579; Abcam). Control cells were cultured in $\alpha$ MEM CM. Low glucose differentiation or control medium contained $5 \mathrm{mmol} /$ $\mathrm{L}$ glucose, and high glucose differentiation or control medium contained $33 \mathrm{mmol} / \mathrm{L}$ glucose.

\section{MSCs: differentiation to myofibroblasts}

Sorted CD $45^{-}$bone marrow stromal cells were seeded in 24-well plates $\left(2.5 \times 10^{4} /\right.$ well $)$. Myofibroblast differentiation was induced for 6 days with $\alpha$ MEM CM supplemented with $2 \mathrm{ng} / \mathrm{mL}$ recombinant human TGF $\beta 1$ (Peprotech) and confirmed with gene expression analysis. Control cells were cultured in $\alpha$ MEM CM.

\section{Analysis of MSC immunosuppressive activity in vivo}

C57B16 $\times$ FVB mice were injected intravenously with 1 million of MSC Hmoxl $I^{+/+}$or Hmoxl ${ }^{-/-}$, or saline (vehicle control) and sacrificed $24 \mathrm{~h}$ later. Numbers of circulating $\mathrm{CD}^{+}$ $\mathrm{T}$ cells, $\mathrm{CD}^{+}$Annexin $\mathrm{V}^{+}$apoptotic $\mathrm{T}$ cells, and $\mathrm{CD} 3^{+} \mathrm{CD} 4^{+}$ $\mathrm{CD} 25^{\text {high }}$ activated $\mathrm{T}$ cells were assessed by flow cytometry on an LSR Fortessa cytometer (Becton Dickinson). Peripheral blood (PB) was collected in heparinized tubes. Red blood cells were lysed with ammonium chloride red blood cell lysis buffer $\left(0.15 \mathrm{M} \mathrm{NH}_{4} \mathrm{Cl}, 10 \mathrm{~m} M \mathrm{KHCO}_{3}, 0.1 \mathrm{~m} M\right.$ EDTA). Obtained total nucleated cells were resuspended in autoMACS Running Buffer (Miltenyi).

Cells were then stained with anti-mouse $\mathrm{CD} 3$ (clone 17A2; BD Horizon), anti-mouse CD4 (clone RPA-T4; BD Horizon), anti-mouse CD25 (clone C37; BD Pharmingen), and antimouse CD45 (clone 30-F11; BD Pharmingen) antibodies. Annexin $\mathrm{V}^{+}$cells were stained with $\mathrm{TACS}^{\circledR}$ Annexin V (AnV) kit (Trevigen) according to the manufacturer's instructions. The number of cells per $1 \mu \mathrm{L}$ of $\mathrm{PB}$ was calculated based on the total leukocyte count (WBC, $10^{3}$ cells $/ 1 \mu \mathrm{L}$ of $\mathrm{PB})$ and the percentage of each population within the collected events. WBC was measured by using ABC Vet (scil animal care $\mathrm{GmbH}$ ).

\section{Analysis of MSC immunosuppressive activity in vitro}

MSC $\mathrm{Hmoxl}^{+/+}$or Hmoxl ${ }^{-/-}$were seeded on six-well plates. When MSCs reached $100 \%$ confluency, they were cocultured for $24 \mathrm{~h}$ with $1 \mathrm{mln}$ of primary mouse splenocytes in each well. After the co-culture, splenocytes were harvested and stained with anti-CD3-AlexaFluor 647 (clone 17A2; BD Pharmingen), anti-Ki67-AlexaFluor 488 (clone B56; BD Pharmingen), and DAPI for the analysis of cell proliferation or with anti-CD3-AlexaFluor 647 (clone 17A2; BD Pharmingen), and Anexin V-FITC (Trevigen) for the analysis of T cell apoptosis. Data are presented as percent of proliferating/ apoptotic $\mathrm{T}$ cells within the population of $\mathrm{CD}^{+} \mathrm{T}$ cells.

\section{Total antioxidant capacity assays}

Total antioxidant capacity of conditioned media from MSC Hmoxl $I^{+/+}$or $\mathrm{Hmoxl}^{-/-}$was measured with TAC Assay (Cell Biolabs) according to the manufacturer's protocol, or using ABTS, or FRAP method. ABTS assay was performed according to the previously published protocol (40) based on the (12) method. FRAP assay was based on the Benzie and Strain method (4).

\section{Multiplex immunoassays}

Levels of factors produced by MSC Hmoxl $\mathrm{I}^{+/+}$or Hmoxl $\mathrm{H}^{-/}$ were measured with Milliplex ${ }^{\circledR}$ MAP Mouse Cytokine/ Chemokine Bead Panel -32 Plex (Millipore) on Luminex FlexMap 3D platform (Millipore) and analyzed with Milliplex Analyst 3.4 software (Millipore).

\section{Proliferation assay}

The proliferation of MSCs was assessed with the BrdU method by using Cell Proliferation ELISA (Roche), according to the manufacturer's protocol. Low glucose medium contained $5 \mathrm{mmol} / \mathrm{L}$ glucose, and high glucose medium contained $33 \mathrm{mmol} / \mathrm{L}$ glucose. Cells were cultured in high or low glucose medium and BrdU labeling solution for $24 \mathrm{~h}$.

\section{Lactate dehydrogenase activity assay}

Cytotoxicity of hemin or $\mathrm{H}_{2} \mathrm{O}_{2}$ in MSCs was evaluated with CytoTox $96^{\circledR}$ NonRadioactive Cytotoxicity Assay (Promega), according to the manufacturer's protocol. Low glucose medium contained $5 \mathrm{mmol} / \mathrm{L}$ glucose, and high glucose medium contained $33 \mathrm{mmol} / \mathrm{L}$ glucose. Cells were treated with hemin, $\mathrm{H}_{2} \mathrm{O}_{2}$, and/or high glucose for $6 \mathrm{~h}$ before the analysis. 


\section{7-aminoactinomycin D-based cell viability assay}

The viability of MSCs stimulated for $6 \mathrm{~h}$ with high doses of hemin was assessed by 7-aminoactinomycin D (7-AAD) staining. Stimulated and control cells were detached with trypsin, washed with PBS, and resuspended in AutoMACS Running Buffer (Miltenyi). Then, cells were stained for 10 min with 7-AAD (BD Pharmingen) according to the manufacturer's protocol and analyzed on a BD LSR Fortessa cytometer.

\section{Measurement of MSC viability in response to $T N F \alpha$}

MSC Hmoxl $I^{+/+}$or Hmoxl ${ }^{-/-}$were incubated with $10 \mathrm{ng} / \mathrm{mL}$ $\mathrm{TNF} \alpha$ for $24 \mathrm{~h}$. Then, numbers of early and late apoptotic cells were assessed by flow cytometry by using the staining with Hoechst 33342 and 7-AAD according to the protocol by Schmid et al. (45).

\section{Measurement of cellular $\mathrm{H}_{2} \mathrm{O}_{2}$ levels}

Levels of cellular $\mathrm{H}_{2} \mathrm{O}_{2}$ were measured with $\mathrm{H}_{2}$ DCFDA assay. Hmoxl $1^{+/+}$or Hmoxl $1^{-/-}$MSCs and fibroblasts were stimulated for 6,24 , or $48 \mathrm{~h}$ with $50 \mu \mathrm{mol} / \mathrm{L}$ hemin (Frontiers Scientific). After each timepoint, the stimulated cells and nonstimulated controls were harvested with trypsin, washed with PBS, and stained for $30 \mathrm{~min}$ with $0.1 \mu \mathrm{mol} / \mathrm{L} \mathrm{H}_{2}$ DCFDA (Sigma-Aldrich) in PBS. Then, cells were washed twice with PBS, and DCFDA fluorescence was assessed with a BD LSR Fortessa cytometer (Becton Dickinson).

\section{Heme cellular content assay}

MSCs Hmoxl $1^{+/+}$or Hmoxl $1^{-/}$were cultured in 24-well plates. Heme content was assessed with the method by Foresti et al. (15) in nonstimulated cells (T0), after $2 \mathrm{~h}$ of stimulation with $50 \mu \mathrm{mol} / \mathrm{L}$ hemin (T2) and after 2 additional hours of culture in fresh $\alpha$ MEM CM (T4). Cells were lysed with $80 \%$ formic acid (POCH S.A.), and the lysate was transferred to clear plastic 96-well plates. Absorbance was measured at $\lambda=398 \mathrm{~nm}$ with a GENios microplate reader (Tecan)

\section{SnPP binding assay}

Cells stimulated with SnPP (Frontiers Scientific) show fluorescence in APC channel $\left(\lambda_{\mathrm{ex}}=640 \mathrm{~nm}\right.$, emission detected with $670 / 25$ bandpass filter). Therefore, we stimulated $H \operatorname{mox} 1^{+/+}$and Hmoxl $1^{-/-}$MSCs with 10,25 , or $50 \mu \mathrm{mol} / \mathrm{L}$ $\mathrm{SnPP}$ for $6 \mathrm{~h}$ and analyzed their fluorescence with flow cytometry. Cells were detached with trypsin, washed, and resuspended in AutoMACS Running Buffer (Miltenyi). Flow cytometry analysis was performed on a BD LSR Fortessa cytometer (Becton Dickinson).

\section{GSH/GSSG assay}

Levels of total GSH, total GSSG, and GSH/GSSG ratio in MSCs and fibroblasts were assessed with GSH/GSSG-Glo ${ }^{\mathrm{TM}}$ Assay (Promega) according to the manufacturer's protocol. Then, $1.0 \times 10^{4}$ cells were seeded per well in 96-well plates. Cells were stimulated for $4 \mathrm{~h}$ with $50 \mu \mathrm{mol} / \mathrm{L}$ hemin in $\alpha \mathrm{MEM}$ $\mathrm{CM}$ and cultured for $2 \mathrm{~h}$ in $\alpha \mathrm{MEM} \mathrm{CM}$ to let them recover GSH levels. Total GSH and total GSSG data are shown as a ratio to the control nonstimulated cells.

\section{Analysis of gene expression}

Total RNA was isolated by phenol-chloroform extraction, and it was reverse transcribed with the oligo(dT) primers and RevertAid Reverse transcriptase (Fermentas) or with the NCode $^{\mathrm{TM}}$ VILO $^{\mathrm{TM}}$ miRNA cDNA synthesis kit (Invitrogen). The expression of genes was assessed by quantitative realtime PCR (qRT-PCR), which was performed in the StepOnePlus system (Applied Biosystems, Foster City, CA) with the specific primers (Supplementary Tables S1 and S2), cDNA and SYBR Green Quantitative RT-PCR kit (SigmaAldrich), under conditions summarized in Supplementary Table S3.

Expression of lipid metabolism genes in $\mathrm{Hmox}^{+/+}$or Hmox $1^{-/-}$MSCs differentiated to adipocytes was assessed with TaqMan ${ }^{\circledR}$ Array Mouse Lipid-Regulated Genes (Applied Biosystems) and TaqMan Universal PCR Master Mix (Applied Biosystems) with the PCR program described in Supplementary Table S3.

\section{Statistical analysis}

Statistical analysis of the data was performed with GraphPad Prism software. Results are expressed as mean \pm SD unless otherwise stated. Statistical significance was accepted at $p<0.05$. Data obtained in in vitro experiments were analyzed with Student's $t$-test when two groups of samples were used. In another case, we used one-way or two-way analysis of variance with Bonferroni post-test. The kind of statistical test applied to analyze given sets of data is provided in the description of figures.

\section{Acknowledgments}

This work was supported by the Polish National Science Centre (grants 2013/11/N/NZ3/00958, 2013/11/N/NZ1/ 02399, 2015/18/NZ3/00387), the European Union under the European Regional Development Fund Operational Programme Innovative Economy 2007-2013 (POIG-01.02.01109/09), and the grant from the National Centre for Research and Development (STRATEGMED (2/269415/11/NCBR/ 2015). WNN was supported by the Foundation for Polish Science (FNP). The Faculty of Biochemistry, Biophysics and Biotechnology of Jagiellonian University is a partner of the Leading National Research Center (KNOW) that is supported by the Ministry of Science and Higher Education. Servier Medical Art image bank was used to prepare Figure 5A.

\section{Author Disclosure Statement}

No competing financial interests exist.

\section{References}

1. Akiyama K, Chen C, Wang D, Xu X, Qu C, Yamaza T, Cai T, Chen W, Sun L, and Shi S. Mesenchymal-stemcell-induced immunoregulation involves FAS-ligand-/FASmediated T cell apoptosis. Cell Stem Cell 10: 544-555, 2012.

2. Ankrum JA, Ong JF, and Karp JM. Mesenchymal stem cells: immune evasive, not immune privileged. Nat Biotechnol 32: 252-260, 2014.

3. Barbagallo I, Vanella A, Peterson SJ, Kim DH, Tibullo D, Giallongo C, Vanella L, Parrinello N, Palumbo GA, Di Raimondo F, Abraham NG, and Asprinio D. Overexpression of heme oxygenase-1 increases human osteo- 
blast stem cell differentiation. J Bone Miner Metab 28: 276-288, 2009.

4. Benzie IF and Strain JJ. Ferric reducing/antioxidant power assay: direct measure of total antioxidant activity of biological fluids and modified version for simultaneous measurement of total antioxidant power and ascorbic acid concentration. Methods Enzymol 299: 15-27, 1999.

5. Bianco P. "Mesenchymal" stem cells. Annu Rev Cell Dev Biol 30: 677-704, 2014.

6. Caplan AI. Mesenchymal stem cells. J Orthop Res 9: 641650, 1991.

7. Chabannes D, Hill M, Merieau E, Rossignol J, Brion R, Soulillou JP, Anegon I, and Cuturi MC. A role for heme oxygenase- 1 in the immunosuppressive effect of adult rat and human mesenchymal stem cells. Blood 110: 36913694, 2007.

8. Ding L, Saunders TL, Enikolopov G, and Morrison SJ. Endothelial and perivascular cells maintain haematopoietic stem cells. Nature 481: 457-462, 2012.

9. Dominici M, Le Blanc K, Mueller I, Slaper-Cortenbach I, Marini F, Krause D, Deans R, Keating A, Prockop Dj, and Horwitz E. Minimal criteria for defining multipotent mesenchymal stromal cells. The International Society for Cellular Therapy position statement. Cytotherapy 8: 315-317, 2006.

10. Dulak J, Deshane J, Jozkowicz A, and Agarwal A. Heme oxygenase-1 and carbon monoxide in vascular pathobiology: focus on angiogenesis. Circulation 117: 231-241, 2008.

11. Eggenhofer E, Benseler V, Kroemer A, Popp FC, Geissler EK, Schlitt HJ, Baan CC, Dahlke MH, and Hoogduijn MJ. Mesenchymal stem cells are short-lived and do not migrate beyond the lungs after intravenous infusion. Front Immunol 3: 297, 2012.

12. Erel O. A novel automated direct measurement method for total antioxidant capacity using a new generation, more stable ABTS radical cation. Clin Biochem 37: 277-285, 2004.

13. Fisher AB. Peroxiredoxin 6: a bifunctional enzyme with glutathione peroxidase and phospholipase $\mathrm{A}^{2}$ activities. Antioxid Redox Signal 15: 831-844, 2011.

14. Florczyk U, Jazwa A, Maleszewska M, Mendel M, Szade K, Kozakowska M, Grochot-Przeczek A, Viscardi M, Czauderna S, Bukowska-Strakova K, Kotlinowski J, Jozkowicz A, Loboda A, and Dulak J. Nrf2 regulates angiogenesis: effect on endothelial cells, bone marrowderived proangiogenic cells and hind limb ischemia. Antioxid Redox Signal 20: 1693-1708, 2014.

15. Foresti R, Hoque M, Bains S, Green CJ, and Motterlini R. Haem and nitric oxide: synergism in the modulation of the endothelial haem oxygenase-1 pathway. Biochem $J$ 372(Pt 2): 381-390, 2003.

16. Grochot-Przeczek A, Kotlinowski J, Kozakowska M, Starowicz K, Jagodzinska J, Stachurska A, Volger OL, Bukowska-Strakova K, Florzyk U, Tertil M, Jazwa A, Szade K, Stepniewski J, Loboda A, Horrevoets AJ, Dulak J, and Jozkowicz A. Heme oxygenase-1 is required for angiogenic function of bone marrow-derived progenitor cells: role in therapeutic revascularization. Antioxid Redox Signal 20: 1677-1692, 2014.

17. Grundemar L and Ny L. Pitfalls using metalloporphyrins in carbon monoxide research. Trends Pharmacol Sci 18: 193195, 1997.

18. Hamedi-Asl P, Halabian R, Bahmani P, Mohammadipour M, Mohammadzadeh M, Roushandeh AM, Jahanian-
Najafabadi A, Kuwahara Y, and Roudkenar MH. Adenovirusmediated expression of the HO-1 protein within MSCs decreased cytotoxicity and inhibited apoptosis induced by oxidative stresses. Cell Stress Chaperones 17: 181-190, 2011.

19. Ho P-J, Yen M-L, Tang B-C, Chen C-T, and Yen BL. $\mathrm{H} 2 \mathrm{O} 2$ accumulation mediates differentiation capacity alteration, but not proliferative decline, in senescent human fetal mesenchymal stem cells. Antioxid Redox Signal 18: 1895-1905, 2013.

20. Hou C, Shen L, Huang Q, Mi J, Wu Y, Yang M, Zeng W, $\mathrm{Li}$ L, Chen W, and Zhu C. The effect of heme oxygenase-1 complexed with collagen on MSC performance in the treatment of diabetic ischemic ulcer. Biomaterials 34: 112120, 2013.

21. Jain A, Lamark T, Sjřttem E, Larsen KB, Awuh JA, Øvervatn A, McMahon M, Hayes JD, and Johansen T. P62/SQSTM1 is a target gene for transcription factor NRF2 and creates a positive feedback loop by inducing antioxidant response element-driven gene transcription. $J$ Biol Chem 285: 22576-22591, 2010.

22. Jaishankar A, Barthelery M, Freeman WM, Salli U, Ritty TM, and Vrana KE. Human embryonic and mesenchymal stem cells express different nuclear proteomes. Stem Cells Dev 18: 793-802, 2009.

23. Jozkowicz A and Dulak J. Effects of protoporphyrins on production of nitric oxide and expression of vascular endothelial growth factor in vascular smooth muscle cells and macrophages. Acta Biochim Pol 50: 69-79, 2003.

24. Kasper G, Mao L, Geissler S, Draycheva A, Trippens J, Kühnisch J, Tschirschmann M, Kaspar K, Perka C, Duda GN, and Klose J. Insights into mesenchymal stem cell aging: involvement of antioxidant defense and actin cytoskeleton. Stem Cells 27: 1288-1297, 2009.

25. Kim KB, Chae YC, Han A, Kang JY, Jung H, Park JW, Hahm JY, Kim S, and Seo SB. Negative regulation of peroxiredoxin 6 (Prdx 6) transcription by nuclear oncoprotein DEK during leukemia cell differentiation. Anim Cells Syst 18: 318-323, 2014.

26. Kim YJ, Hwang SJ, Bae YC, and Jung JS. MiR-21 regulates adipogenic differentiation through the modulation of TGF-beta signaling in mesenchymal stem cells derived from human adipose tissue. Stem Cells 27: 3093-3102, 2009.

27. Kozakowska M, Ciesla M, Stefanska A, Skrzypek K, Was H, Jazwa A, Grochot-Przeczek A, Kotlinowski J, Szymula A, Bartelik A, Mazam M, Yagensky O, Florczyk U, Lemke K, Zebzda A, Dyduch G, Nowak W, Szade K, Stepniewski J, Majka M, Derlacz R, Loboda A, Dulak J, and Jozkowicz A. Heme oxygenase-1 inhibits myoblast differentiation by targeting myomirs. Antioxid Redox Signal 16: 113-127, 2012.

28. Kumar S and Bandyopadhyay U. Free heme toxicity and its detoxification systems in human. Toxicol Lett 157: 175-188, 2005.

29. Laird MD, Wakade C, Alleyne CH Jr, and Dhandapani KM. Hemin-induced necroptosis involves glutathione depletion in mouse astrocytes. Free Radic Biol Med 45: 1103-1114, 2008.

30. Lee CH, Shah B, Moioli EK, and Mao JJ. CTGF directs fibroblast differentiation from human mesenchymal stem/stromal cells and defines connective tissue healing in a rodent injury model. J Clin Invest 120: 3340-3349, 2010 . 
31. Lin CY, Peng CY, Huang TT, Wu ML, Lai YL, Peng DH, Chen PF, Chen HF, Yen BL, Wu KK, and Yet SF. Exacerbation of oxidative stress-induced cell death and differentiation in induced pluripotent stem cells lacking heme oxygenase-1. Stem Cells Dev 21: 1675-1687, 2012.

32. Lin TH, Tang CH, Hung SY, Liu SH, Lin YM, Fu WM, and Yang RS. Upregulation of heme oxygenase-1 inhibits the maturation and mineralization of osteoblasts. J Cell Physiol 222: 757-768, 2010.

33. Mabuchi Y, Morikawa S, Harada S, Niibe K, Suzuki S, Renault-Mihara F, Houlihan DD, Akazawa C, Okano H, and Matsuzaki Y. LNGFR(+)THY-1(+)VCAM-1(hi+) cells reveal functionally distinct subpopulations in mesenchymal stem cells, Stem Cell Reports 1: 152-165, 2013.

34. Méndez-Ferrer S, Michurina TV, Ferraro F, Mazloom AR, Macarthur BD, Lira SA, Scadden DT, Ma'ayan A, Enikolopov GN, and Frenette PS. Mesenchymal and haematopoietic stem cells form a unique bone marrow niche. Nature 466: 829-834, 2010.

35. Mishra PJ, Humeniuk R, Medina DJ, Alexe G, Mesirov JP, Ganesan S, Glod JW, and Banerjee D. Carcinomaassociated fibroblast-like differentiation of human mesenchymal stem cells. Cancer Res 68: 4331-4339, 2008.

36. Morikawa S, Mabuchi Y, Kubota Y, Nagai Y, Niibe K, Hiratsu E, Suzuki S, Miyauchi-Hara C, Nagoshi N, Sunabori T, Shimmura S, Miyawaki A, Nakagawa T, Suda T, Okano H, and Matsuzaki Y. Prospective identification, isolation, and systemic transplantation of multipotent mesenchymal stem cells in murine bone marrow. $J$ Exp Med 206: 2483-2496, 2009.

37. Mougiakakos D, Jitschin R, Johansson CC, Okita R, Kiessling R, and Le Blanc $\mathrm{K}$. The impact of inflammatory licensing on heme oxygenase-1-mediated induction of regulatory $\mathrm{T}$ cells by human mesenchymal stem cells. Blood 117: 4826-4835, 2011.

38. Munakata $H$. Role of the heme regulatory motif in the heme-mediated inhibition of mitochondrial import of 5aminolevulinate synthase. J Biochem 136: 233-238, 2004.

39. Nauta AJ and Fibbe WE. Immunomodulatory properties of mesenchymal stromal cells. Blood 110: 3499-3506, 2007.

40. Nowak WN, Borys S, Kusińska K, Bukowska-Strakova K, Witek P, Koblik T, Józkowicz A, Małecki MT, and Dulak J. Number of circulating pro-angiogenic cells, growth factor and anti-oxidative gene profiles might be altered in type 2 diabetes with and without diabetic foot syndrome. $J$ Diabetes Investig 5: 99-107, 2014.

41. Omatsu Y, Sugiyama T, Kohara H, Kondoh G, Fujii N, Kohno K, and Nagasawa T. The essential functions of adipo-osteogenic progenitors as the hematopoietic stem and progenitor cell niche. Immunity 33: 387-399, 2010.

42. Poss $\mathrm{KD}$ and Tonegawa $\mathrm{S}$. Heme oxygenase 1 is required for mammalian iron reutilization. Proc Natl Acad Sci USA 94: 10919-10924, 1997.

43. Puri N, Sodhi K, Haarstad M, Kim DH, Bohinc S, Foglio E, Favero G, and Abraham NG. Heme induced oxidative stress attenuates sirtuin1 and enhances adipogenesis in mesenchymal stem cells and mouse pre-adipocytes. J Cell Biochem 113: 1926-1935, 2012.

44. Sacchetti B, Funari A, Michienzi S, Di Cesare S, Piersanti S, Saggio I, Tagliagico E, Ferrari S, Robey PG, Riminucci $\mathrm{M}$, and Bianco P. Self-renewing osteoprogenitors in bone marrow sinusoids can organize a hematopoietic microenvironment. Cell 131: 324-336, 2007.
45. Schmid I, Uittenbogaart C, and Jamieson BD. Live-cell assay for detection of apoptosis by dual-laser flow cytometry using Hoechst 33342 and 7-amino-actinomycin D. Nat Protoc 2: 187-190, 2007.

46. Sedlak TW, Saleh M, Higginson DS, Paul BD, Juluri KR, and Snyder SH. Bilirubin and glutathione have complementary antioxidant and cytoprotective roles. Proc Natl Acad Sci USA 106: 5171-5176, 2009.

47. Stachurska A, Ciesla M, Kozakowska M, Wolffram S, Boesch-Saadatmandi C, Rimbach G, Jozkowicz A, Dulak J, and Loboda A. Cross-talk between microRNAs, nuclear factor E2-related factor 2, and heme oxygenase-1 in ochratoxin A-induced toxic effects in renal proximal tubular epithelial cells. Mol Nutr Food Res 57: 504-515, 2012.

48. Starzyński RR, Canonne Hergaux F, Lenartowicz M, Krzeptowski W, Willemetz A, Stys A, Bierla J, Pietrzak P, Dziaman T, and Lipinski P. Ferroportin expression in haem oxygenase 1-deficient mice. Biochem J 449: 69-78, 2012.

49. Stepniewski J, Kachamakova-Trojanowska N, Ogrocki D, Szopa M, Matlok M, Beilharz M, Dyduch G, Malecki MT, Jozkowicz A, and Dulak J. Induced pluripotent stem cells as a model for diabetes investigation. Sci Rep 5: 8597, 2015.

50. Stocker R, Yamamoto Y, McDonagh AF, Glazer AN, and Ames BN. Bilirubin is an antioxidant of possible physiological importance. Science 235: 1043-1046, 1987.

51. Su J, Chen X, Huang Y, Li W, Li J, Cao K, Cao G, Zhang L, Li F, Roberts AI, Kang H, Yu P, Ren G, Ji W, Wang Y, and Shi Y. Phylogenetic distinction of iNOS and IDO function in mesenchymal stem cell-mediated immunosuppression in mammalian species 21: 388-396, 2013.

52. Sun J, Hoshino H, Takaku K, Nakajima O, Muto A, Suzuki H, Tashiro S, Takahashi S, Shibahara S, Alam J, Taketo MM, Yamamoto M, and Igarashi K. Hemoprotein Bach1 regulates enhancer availability of heme oxygenase-1 gene. EMBO J 21: 5216-5224, 2002.

53. Taha H, Skrzypek K, Guevara I, Nigisch A, Mustafa S, Grochot-Przeczek A, Ferdek P, Was H, Kotlinoski J, Kozakowska M, Balcerczyk A, Muchova L, Vitek L, Weigel G, Dulak J, and Jozkowicz A. Role of heme oxygenase-1 in human endothelial cells: lesson from the promoter allelic variants. Arterioscler Thromb Vasc Biol 30: 1634-1641, 2010.

54. Tsubokawa T, Yagi K, Nakanishi C, Zuka M, Nohara A, Ino H, Fujino N, Konno T, Kawashiri MA, Ishibashi-Ueda $\mathrm{H}$, Nagaya $\mathrm{N}$, and Yamagishi $\mathrm{M}$. Impact of anti-apoptotic and anti-oxidative effects of bone marrow mesenchymal stem cells with transient overexpression of heme oxygenase-1 on myocardial ischemia. Am J Physiol Heart Circ Physiol 298: H1320-H1329, 2010.

55. Valle-Prieto A and Conget PA. Human mesenchymal stem cells efficiently manage oxidative stress. Stem Cells Dev 19: 1885-1893, 2010.

56. Vanella L, Kim DH, Asprinio D, Peterson SJ, Barbagallo I, Vanella A, Goldstein D, Ikehara S, Kappas A, and Abraham NG. HO-1 expression increases mesenchymal stem cell-derived osteoblasts but decreases adipocyte lineage. Bone 46: 236-243, 2010.

57. Vanella L, Kim DH, Sodhi K, Barbagallo I, Burgess AP, Faick JR, Schwartzman ML, and Abraham NG. Crosstalk between EET and HO-1 downregulates Bach1 and adipogenic marker expression in mesenchymal stem cell derived adipocytes. Prostaglandins Other Lipid Mediat 96: 54-62, 2011. 
58. Vanella L, Sanford C, Kim DH, Abraham NG, and Ebraheim N. Oxidative stress and heme oxygenase-1 regulated human mesenchymal stem cells differentiation. Int $\mathrm{J} \mathrm{Hy}$ pertens 2012: 1-10, 2012.

59. Vanella L, Sodhi K, Kim DH, Puri N, Maheshwari M, Hinds TD, Bellner L, Goldstein D, Peterson SJ, Shapiro JI, and Abraham NG. Increased heme-oxygenase 1 expression decreases adipocyte differentiation and lipid accumulation in mesenchymal stem cells via upregulation of the canonical Wnt signaling cascade. Stem Cell Res Ther 4: 28, 2013.

60. Wagner W, Feldmann RE Jr., Seckinger A, Maurer MH, Wein F, Blake J, Krause U, Kalenka A, Bürgers HF, Saffrich R, Wuchter P, Kuschinsky W, and Ho AD. The heterogeneity of human mesenchymal stem cell preparations-evidence from simultaneous analysis of proteomes and transcriptomes. Exp Hematol 34: 536548, 2006.

61. Warnatz HJ, Schmidt D, Manke T, Piccini I, Sultan M, Borodina T, Balzereit D, Wruck W, Soldatov A, Vingron M, Lehrach H, and Yaspo ML. The BTB and CNC homology 1 (BACH1) target genes are involved in the oxidative stress response and in control of the cell cycle. J Biol Chem 286: 23521-23532, 2011.

62. Was H, Sokolowska M, Sierpniowska A, Dominik P, Skrzypek K, Lackowska B, Pratnicki A, Grochot-Przeczek A, Taha H, Kotlinowski J, Kozakowska M, Mazan A, Nowak W, Muchova L, Vitek L, Ratajska A, Dulak J, and Jozkowicz A. Effects of heme oxygenase-1 on induction and development of chemically induced squamous cell carcinoma in mice. Free Radic Biol Med 51: 1717-1726, 2011.

63. Wojakowski W, Tendera M, Cybulski W, Zuba-Surma EK, Szade K, Florczyk U, Kozakowska M, Szymula A, Krzych L, Paslawska U, Pasławski R, Milewski K, Buszman P, Nabiałek E, Kuczmik W, Janiszewski A, Dziȩgiel P, Buszman PE, Józkowicz A, and Wojakowski W. Effects of intracoronary delivery of allogenic bone marrow-derived stem cells expressing heme oxygenase-1 on myocardial reperfusion injury. Thromb Haemost 108: 464-475, 2012.

64. This reference has been deleted.

65. Zarjou A, Jeney V, Arosio P, Poli M, Antal-Szalmas P, Agarwal A, Balla G, and Balla J. Ferritin prevents calcification and osteoblastic differentiation of vascular smooth muscle cells. J Am Soc Nephrol 20: 1254-1263, 2009.

66. Zarjou A, Kim J, Traylor AM, Sanders PW, Balla J, Agarwal A, and Curtis LM. Paracrine effects of mesenchymal stem cells in cisplatin-induced renal injury require heme oxygenase-1. Am J Physiol Renal Physiol 300: F254F262, 2011.
67. Zhou BO, Yue R, Murphy MM, Peyer JG, and Morrison SJ. Leptin-receptor-expressing mesenchymal stromal cells represent the main source of bone formed by adult bone marrow. Cell Stem Cell 15: 154-168, 2014.

68. Zhou H, Ramiya VK, and Visner GA. Bone marrow stem cells as a vehicle for delivery of heme oxygenase-1 gene. Stem Cells Dev 15: 79-86, 2006.

69. Zhu H, Guo ZK, Jiang XX, Li H, Wang XY, Yao HY, Zhang Y, and Mao N. A protocol for isolation and culture of mesenchymal stem cells from mouse compact bone. Nat Protoc 5: 550-560, 2010.

Address correspondence to: Prof. Alicja Józkowicz Department of Medical Biotechnology Faculty of Biochemistry, Biophysics and Biotechnology Jagiellonian University ul. Gronostajowa 7 Kraków 30-387 Poland

E-mail: alicja.jozkowicz@uj.edu.pl

Date of first submission to ARS Central, April 12, 2017; date of final revised submission, October 16, 2017; date of acceptance, October 22, 2017.

$\begin{aligned} & \text { Abbreviations Used } \\ 7-\mathrm{AAD}= & 7 \text {-aminoactinomycin } \mathrm{D} \\ \mathrm{ABTS}= & 2,2^{\prime} \text {-azino-bis }(3 \text {-ethylbenzothiazoline- } \\ & \quad 6 \text {-sulphonic acid) } \\ \mathrm{BDMC}= & \text { bone marrow-derived proangiogenic } \\ & \quad \text { cells } \\ \mathrm{CM}= & \text { complete medium } \\ \mathrm{CoPP}= & \text { cobalt protoporphyrin IX } \\ \mathrm{FRAP}= & \text { ferric-reducing antioxidant power } \\ \mathrm{GSH}= & \text { reduced glutathione } \\ \mathrm{GSSG}= & \text { oxidized glutathione } \\ \mathrm{HO}-1=\text { Heme oxygenase-1 (encoded by the } & \quad \text { HMOX1 gene) } \\ \mathrm{MSCS}= & \text { mesenchymal stromal cells } \\ \mathrm{PAC}= & \text { proangiogenic cell } \\ \mathrm{PB}= & \text { peripheral blood } \\ \mathrm{PGJ} 2= & \text { prostaglandin } \mathrm{J} 2 \\ \mathrm{qRT}-\mathrm{PCR}= & \text { quantitative real-time PCR } \\ \mathrm{SnPP}= & \text { tin protoporphyrin IX } \\ \mathrm{TAC}= & \text { total antioxidant capacity }\end{aligned}$

